\title{
The Effectiveness of Diabetic Shared Medical Appointments to Improve Access and Outcomes
}

Amanda P. Wakim

Follow this and additional works at: https://researchrepository.wvu.edu/etd

\section{Recommended Citation}

Wakim, Amanda P., "The Effectiveness of Diabetic Shared Medical Appointments to Improve Access and Outcomes" (2016). Graduate Theses, Dissertations, and Problem Reports. 6886.

https://researchrepository.wvu.edu/etd/6886

This Dissertation is protected by copyright and/or related rights. It has been brought to you by the The Research Repository @ WVU with permission from the rights-holder(s). You are free to use this Dissertation in any way that is permitted by the copyright and related rights legislation that applies to your use. For other uses you must obtain permission from the rights-holder(s) directly, unless additional rights are indicated by a Creative Commons license in the record and/ or on the work itself. This Dissertation has been accepted for inclusion in WVU Graduate Theses, Dissertations, and Problem Reports collection by an authorized administrator of The Research Repository @ WVU.

For more information, please contact researchrepository@mail.wvu.edu. 
The Effectiveness of Diabetic Shared Medical Appointments to Improve Access and Outcomes

Amanda P Wakim, RN, FNP-BC

Capstone project submitted to the School of Nursing at West Virginia University in partial fulfillment of the requirements for the degree of Doctor of Nursing Practice

\author{
Alvita Nathaniel, PhD, APRN-BC, FAANP, Chair \\ Jennifer A. Mallow PhD, FNP-BC \\ Julie S Bunner, MD
}

School of Nursing

Morgantown, West Virginia

April, 2016

Key Words: Diabetes, Shared Medical Appointments, Chronic Health Care Model, Rural Populations, Endocrinology

Copyright 2016 Amanda Wakim 


\begin{abstract}
Diabetes in Appalachia is a health problem with escalating incidence and cost. The increased aging population and inadequate healthy life choices are main contributors to the diabetes epidemic. As the incidence of diabetes increases, the current one-to-one, patient-toprovider health care delivery system is insufficient to meet the needs of persons with diabetes. Furthermore, as the prevalence of diabetes increases, the access to endocrinologists in northern West Virginia becomes more limited. Increased incidence and decreased access results in poor health outcomes, increased medical costs, and patient and provider dissatisfaction with the health care system. The shared medical appointment (SMA) is an evidence-based approach to health care delivery that provides improved access to care, improved outcomes for patients with diabetes, and reduced cost, while improving patient and provider satisfaction. The purpose of this quality improvement project was to improve patient access to endocrinology care, improve adherence to the ADA standards of care, and improve patient and staff satisfaction with the health care delivery system via implementation of SMAs at an endocrinologist's office in northern West Virginia. The Chronic Care Model (CCM) was used to guide the project. Two cohorts of patients met 11 times at one month intervals. Each SMA consisted of two hour sessions, providing both individual patient-to-provider time, and group meetings. The evaluation of the project was based on increased patient access, adherence to the ADA standards of care, and patient and provider satisfaction. Access to care was increased by 38 more participants. There was no change in adherence to ADA standards of care. Both patient and staff satisfaction indicated statistically significant positive difference between patient/staff satisfaction from preSMA to post-SMA.
\end{abstract}




\section{TABLE OF CONTENTS}

The Effectiveness of Diabetic Shared Medical Appointments to Improve

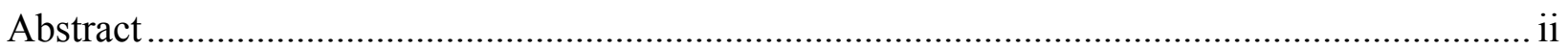

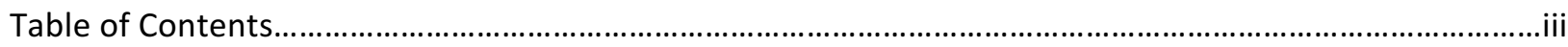

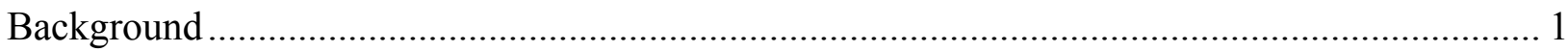

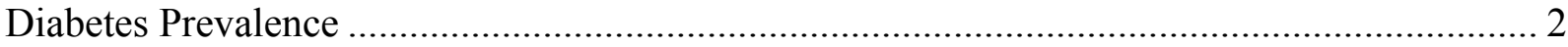

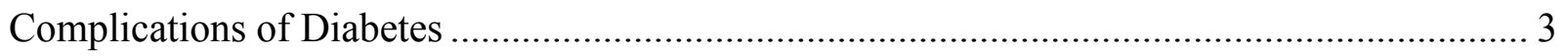

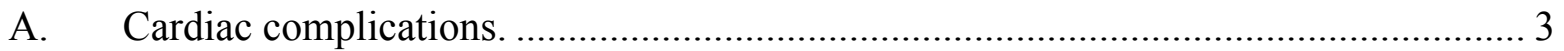

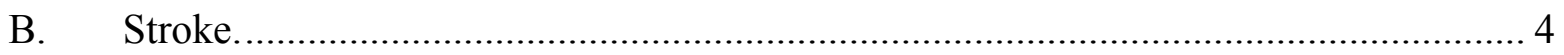

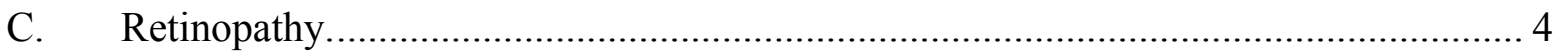

D. End-stage renal disease (ESRD) .............................................................. 4

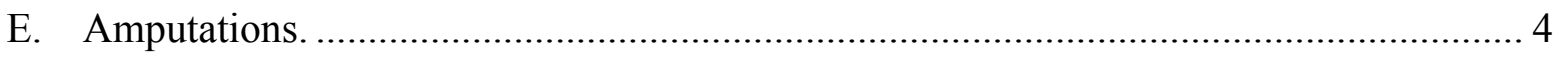

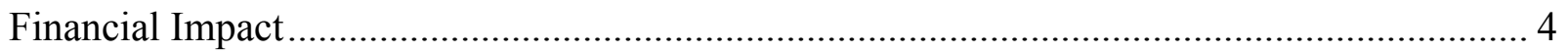

West Virginia Risk Factors ........................................................................................ 5

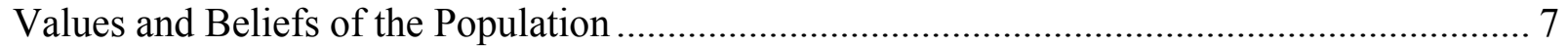

ADA Standards of Care and Patient Compliance ................................................................. 8

Health-Care Delivery System...................................................................................... 10

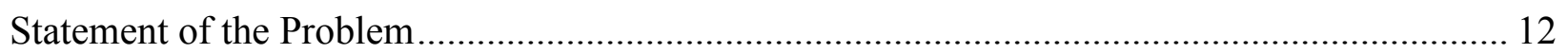

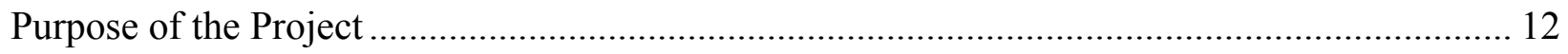

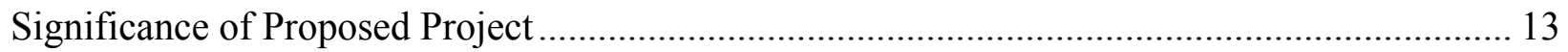

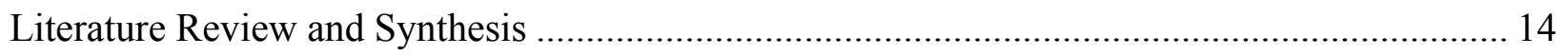

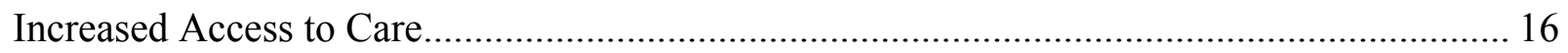

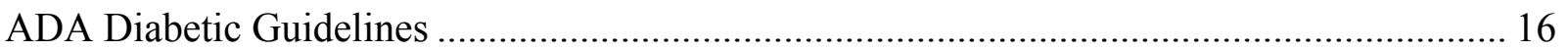

Glycated Hemoglobin (A1C) Outcomes ............................................................................. 18

Evidence of Improved Self-Monitoring .............................................................................. 19

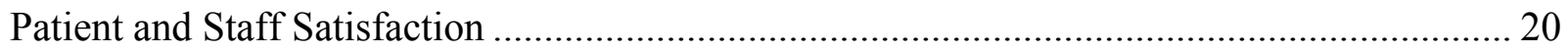

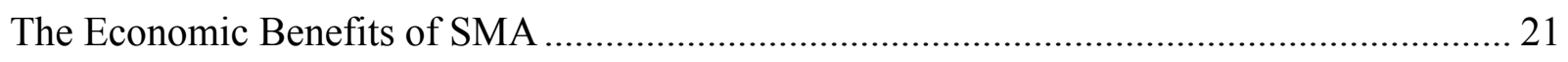

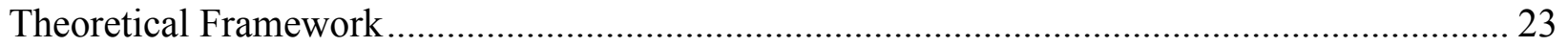

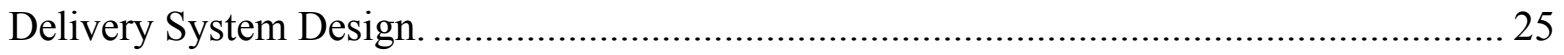

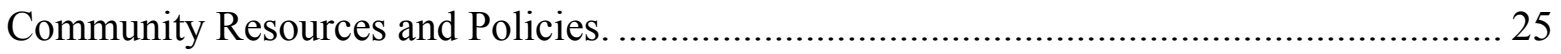

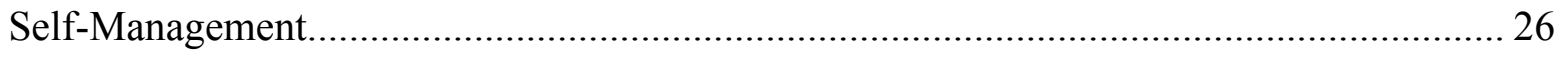

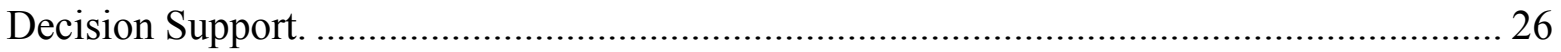

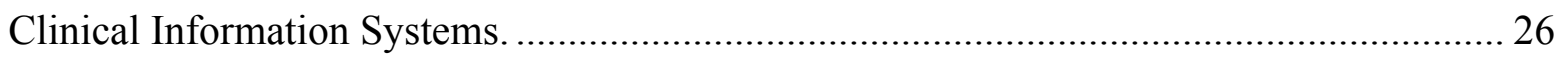




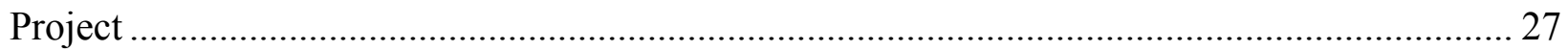

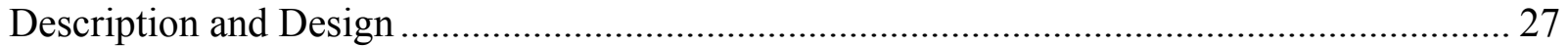

Preplanning Phase

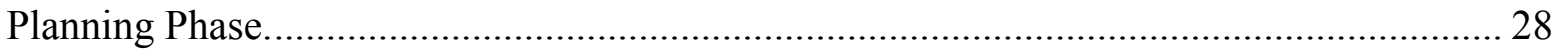

Implementation Phase

Theoretical Framework and the Quality Improvement Project …………………...................... 34

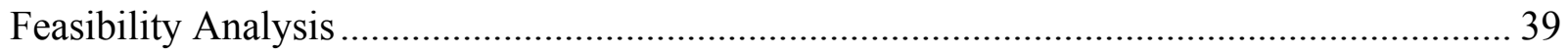

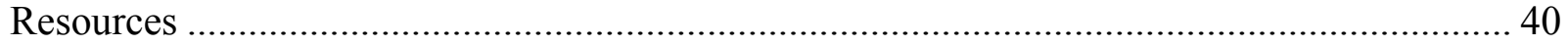

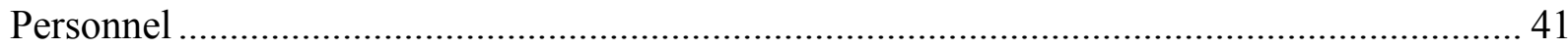

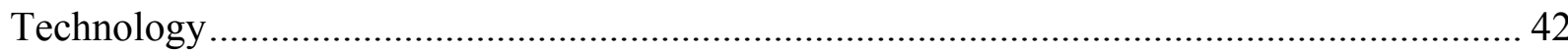

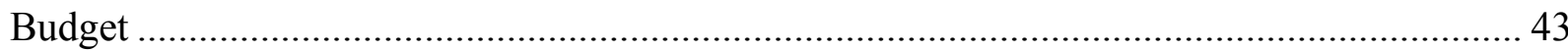

Congruence of Organization's Strategic Plan to Project......................................................... 45

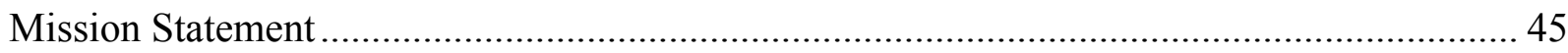

Purpose of the Organizations Quality Process Improvement Statement................................... 45

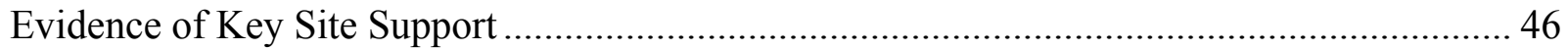

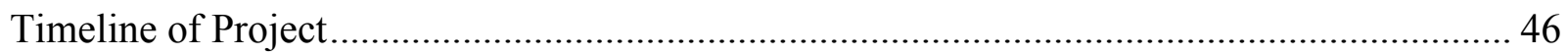

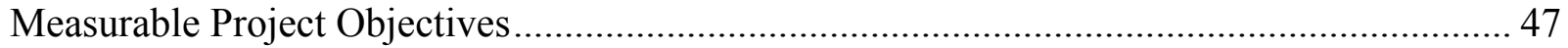

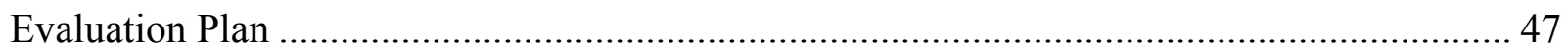

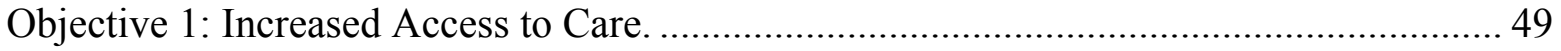

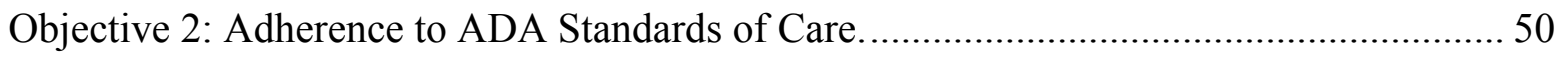

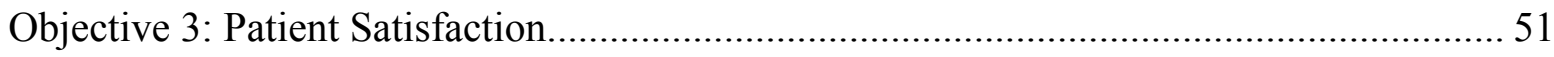

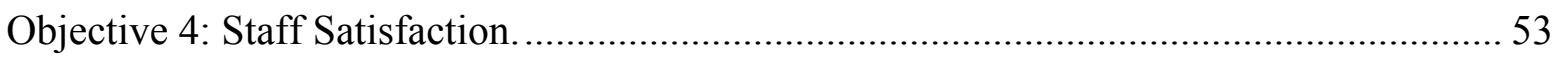

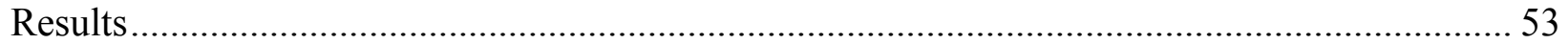

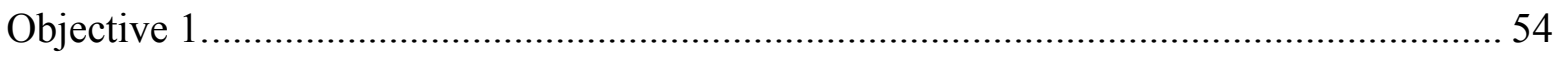

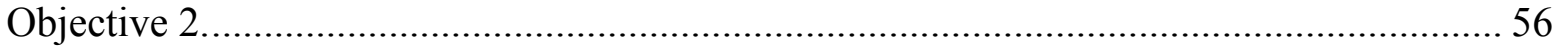

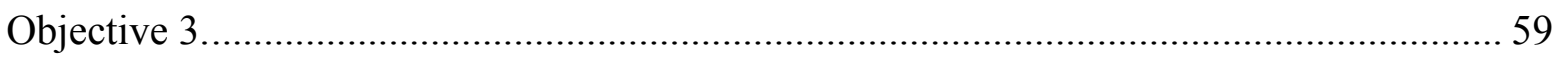

Objective 4

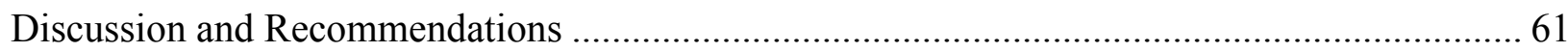

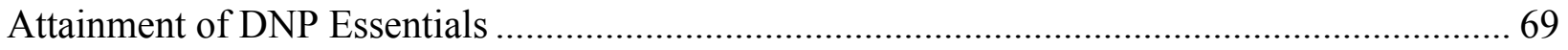

Scientific Underpinnings for Practice ............................................................................... 70

Organizational \&Systems Leadership for Quality Improvement \& Systems Thinking............. 71

Clinical Scholarship and Analytical Methods for Evidence-Based Practice ............................ 72

Information Systems/Technology \& Patient Care Technology for the Improvement \& .......... 73

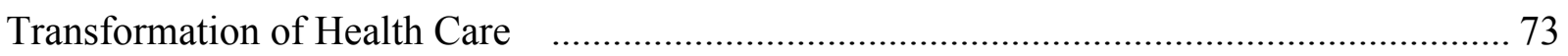

Health Care Policy for Advocacy in Health Care …………............................................... 73

Interprofessional Collaboration for Improving Patient \& Population Health Outcomes......... 73

Clinical Prevention and Population Health for Improving the Nation's Health................79 
Advanced Nursing Practice .................................................................................................. 74

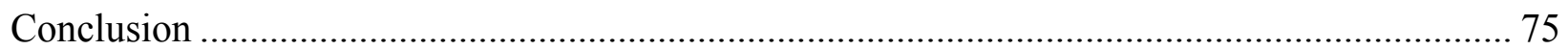

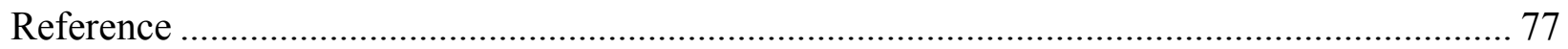

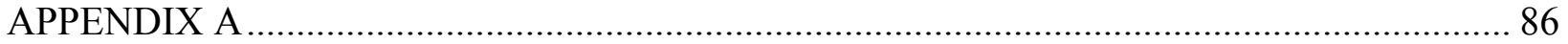

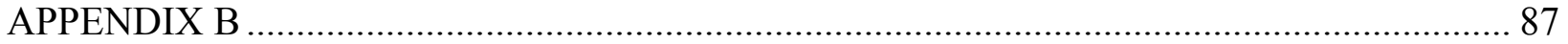

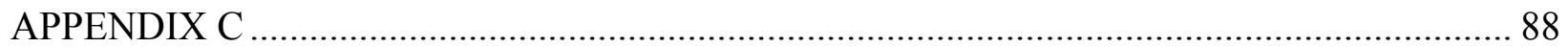

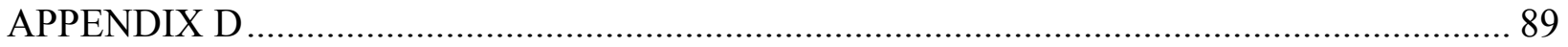

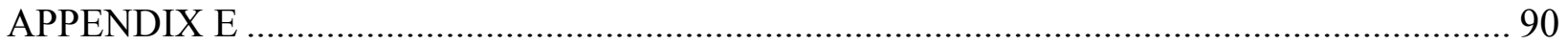

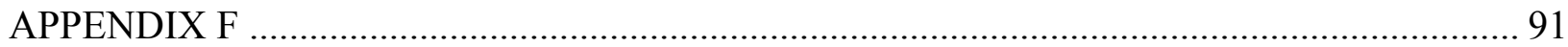

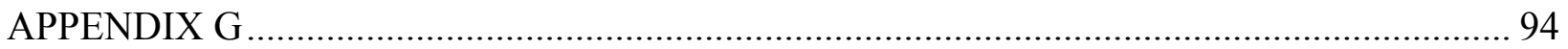

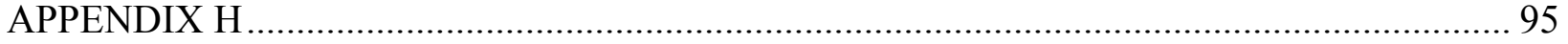

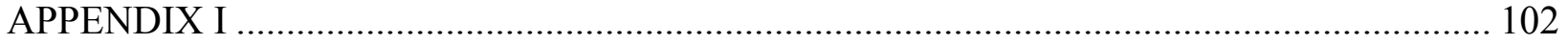

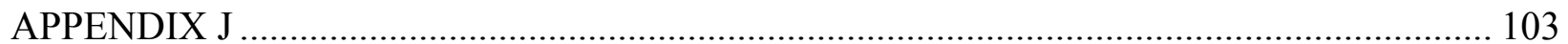

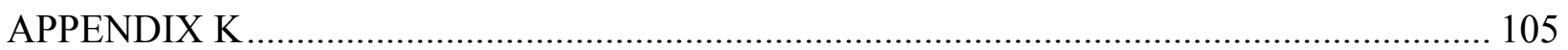

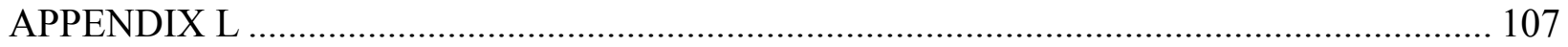

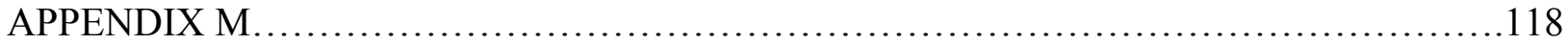

\section{LIST OF TABLES}

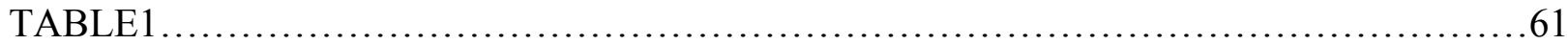

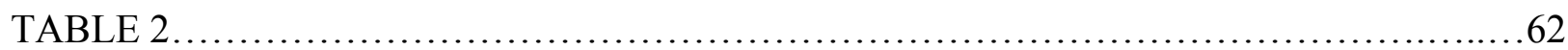

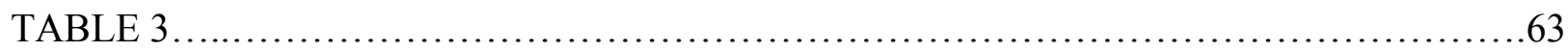

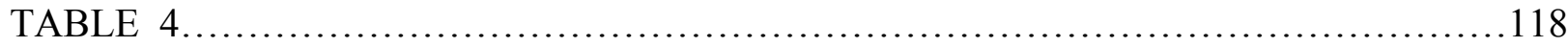


Diabetes in Appalachia is a health problem with escalating incidence and cost. The increased aging population in the area, compounded by inadequate healthy life choices, is one of the main contributors to the diabetes epidemic. The purpose of this quality improvement project was to improve patient access to endocrinology care, improve adherence to the ADA standards of care, and improve patient and staff satisfaction with the health care delivery system via implementation of Shared Medical Appointments (SMA) at an endocrinologist's office in northern West Virginia. The Chronic Care Model was used to guide the project. National and West Virginia diabetes data is presented and compared to the regional diabetes data. The barriers to delivery of quality care in the area are also discussed. In addition, a strategic plan to implement SMA is presented, including strategies to break down the barriers, improve patients' access, improve adherence to ADA standards of care, and evaluate patient and staff satisfaction. Included in this paper are background of the problem, literature review and synthesis, theoretical framework, the quality improvement project, discussion and recommendations, and a discussion of how the capstone met the Doctoral of Nursing (DNP) essentials.

\section{Background}

Diabetes is a devastating chronic disease, which poses multidimensional problems to the nation, West Virginia, and northern West Virginia (CDC, 2014). Following are eight specific problems related to diabetes in West Virginia: 1) There is an increase in the prevalence of the disease. The prevalence of diabetes in West Virginia and in northern West Virginia is higher than the nation as a whole (West Virginia Department of Health \& Human Resources [WVDHHR], 2012). 2) Diabetes leads to major damage to organs, which increases the rate of emergency room visits, hospitalization, and mortality (CDC, 2014). 3) The financial burden of treating 
diabetes is putting an added economic stress on the nation (Herman, 2013). 4) The higher prevalence of diabetes in West Virginia, the only state totally nested in the Appalachian Mountains, may be due to greater social and economic disparities (WVDHH 2012a, WVDHH 2012 b). 5) In West Virginia the risk factors are accentuated by the Appalachian values and belief system (Huttlinger \& Purnell, 2008). 6) The problem is further increased by the lack of patient adherence (Martin,Williams, Haskard, 2005). 7) The increased number of patients that require endocrinology care is affected by a shortage of endocrinologists, which decreases access to care (Vigersky et al. 2014). 8) The current health care delivery system of one-on-one, patientto-provider is insufficient to meet the needs of all the patients (Sikon \& Bronson, 2010). The end results of the eight problems listed above are increased medical costs, increased morbidity and mortality, and a health-care delivery system unable to effectively address the problem. In addition, providers and patients are dissatisfied with the current health care delivery system. (Clancy et al., 2007; Dickman, Pintz, \& Gold, 2012; Trento et al., 2004; and Wagner et al., 2001). The implementation of SMA offers an alternative to the current system.

\section{Diabetes Prevalence}

In 2012, diabetes affected 29.1 million Americans (9.3\% nationally). These numbers reflect 21.0 million Americans that are diagnosed and an estimated 8.1 million that are undiagnosed (Centers for Disease Control and Prevention [CDC] 2014). In the age group of 20 years and above, 1.7 million new cases of diabetes were diagnosed in 2012 (CDC, 2014). The numbers are expected to continue to grow in this age group given that 86 million patients with prediabetes were identified throughout the country between 2009 and 2012. The statistics represent $37 \%$ of the U.S. population, $51 \%$ of whom are 65 and older. 
Hospital visits and death rates due to diabetes are also on the rise. In 2011, the CDC reported that in the U.S. diabetes accounted for 457, 000 emergency room admissions due to hypoglycemia and hyperglycemic crisis, and in 2010 there were a total of 2,361 deaths due hyperglycemic crisis. Furthermore, in 2010 a total of 234,051 death certificates listed diabetes as cause of death (CDC, 2014). Death rates were about 1.5 times higher than for nondiabetic adults aged 18 and older. According to recent studies, the underlying cause of death related to diabetes is likely to be underreported by as much as $35 \%$ to $40 \%$ (CDC, 2014).

Diabetes prevalence among adults in West Virginia has significantly and steadily increased since 1995 (WVDHHR, 2012). In West Virginia, the prevalence for diabetes is 11.7\%, and in northern West Virginia 11.4\%, affecting 4,138 residents. Both prevalence rates are considerably higher than the national rate of 9.3 (WVDHHR, 2012). In West Virginia, diabetes ranks sixth as the leading cause of death compared to seventh in the nation (WVDHHR, 2012).

\section{Complications of Diabetes}

Diabetes is a progressive disease. When not treated appropriately, diabetes leads to devastating multi-organ damage that may result in heart disease, strokes, nerve damage, blindness, kidney failure, and amputations. Other complications of diabetes include nonalcoholic fatty liver, gum disease, loss of hearing, erectile dysfunction, and depression (CDC, 2014). CDC reported that some of the major complications due to diabetes are the following:

A. Cardiac complications. Centers for Disease Control (2014) reported that in 2010 adult patients with diabetes were hospitalized with a myocardial infarction 1.8 times more than patients without diabetes. Between 2003 and 2006 cardiac disease related deaths in diabetics was 1.7 times greater than in nondiabetic patients. 
B. Stroke. In 2010, people with diabetes had 1.5 times higher incidence of strokes than nondiabetics (CDC 2014).

C. Retinopathy. Between 2005 and 2008, 4.2 million patients with diabetes ages forty and over were found to have retinopathy (CDC, 2014).

D. End-stage renal disease (ESRD). The incidence of end-stage renal disease in 2011 among diabetics in the nation was $44 \%$. A total of 49,677 diabetics started treatment for renal damage the same year. Furthermore, 228,924 diabetics in the U.S. were living with kidney disease or with a kidney transplant. (CDC, 2014).

E. Amputations. In 2010, amputations due to diabetes occurred among 73,000 adults over the age of 20. These were non-trauma related lower limb amputations, accounting for about $60 \%$ of all amputations in the nation (CDC, 2014).

\section{Financial Impact}

Diabetes care and its devastating complications contribute to the increase in medical costs (CDC, 2014; Herman, 2013). The American Diabetes Association (2013) reported that total direct and indirect cost for patients with diabetes in 2012 was $\$ 245$ billion. This is a $41 \%$ increase from the 2007 estimates of $\$ 174$ billion. Direct diabetic health cost accounts for $43 \%$ for inpatient care; $18 \%$ for the medications needed to treat the diabetic complication; $12 \%$ for diabetic medications and diabetic supplies; $9 \%$ for outpatient provider appointments; and $8 \%$ for long term care in nursing home settings (Herman, 2013). This accounts for $\$ 176$ billion of direct medical costs, which is 2.3 times higher than direct medical cost for people that do not have diabetes. The indirect cost of disability, work lost, and premature death was reported at $\$ 69$ billion (CDC 2014). Herman, (2013) reported that indirect diabetes health care cost accounts for five billion dollars due to work absenteeism; $\$ 20.8$ billion due to reduced productivity for those 
in the workforce; $\$ 2.7$ billion due to decreased productivity for the unemployed; $\$ 21.6$ billion related to disability; and $\$ 18.5$ billion due to lost productivity and early mortality. Yearly medical cost for the diabetic patient is estimated at $\$ 13,700$, of which $\$ 7,900$ is due to the direct cost of diabetic care. This accounts for a 2.3 times higher cost for the diabetic patient compared to the nondiabetic one. Annual diabetes care cost is expected to increase to \$336 billion by 2034 (Herman, 2013). As diabetes continues to increase, the medical cost will continue to increase.

\section{West Virginia Risk Factors}

West Virginia is the only state that sits entirely in the Appalachian region (WVDHHR, 2013). Increased age, low educational level, and decreased house hold income may be contributing factors that places people at risk for diabetes in West Virginia (WVDHHR, 2012; WVDHHR, 2013). In 2012 the Mountain state had 16.8\% of people age 65 and older compared to $13.7 \%$ in the nation. One in ten adults in West Virginia has diabetes and the incidence of diabetes is highest among people age 65 and older (WVDHHR, 2013). The state's diabetes rate ranks as one the highest in the nation (WVDHHR, 2013).

The level of education appears to impact the incidence of diabetes in West Virginia, as well. Diabetes is more prevalent in people with lower education and West Virginians are more likely to have less education. In 2007 to 2011 people in West Virginia with a high school diploma or higher level of education were $82.6 \%$ compared to $95.4 \%$ in the nation ((WVDHHR, 2013). In West Virginia, 18\% of high school students drop out of school, while only 17\% complete a bachelor's degree or higher compared to $28.2 \%$ in the nation. The incidence of diabetes among people in West Virginia with less than a high school education was at 20.4\% compared to $9.9 \%$ among people who had college education or more (Schenck et al., 2014).

West Virginia is also an economically depressed state and many of its citizens lack funds to 
purchase their medications. West Virginia has one of lowest median household incomes in the nation (WVDHHR, 2013). The average income in West Virginia in 2011 was $\$ 39,550$ compared to $\$ 52,762$ nationwide. This indicates that there are more people in West Virginia living in poverty-17.5\% compared to $14.3 \%$ in the nation (WVDHHR, 2013). Due to this poverty, many people in West Virginia lack financial resources to buy their medications. The problem is compounded because out-of-pocket medication for diabetes appears to be higher than other chronic disease medications (Dubois, Chawla, Neslusan, Smith, \& Wade, 2000). Diabetic medication regimen compliance for patients with diabetes and with low economic status is decreased due to-out-of-pocket expense (Piette, Heisler, \& Wagner, 2004). Due to economic hardship as a consequence about $19 \%$ of these patients go without one or two of the medications needed to manage their diabetes. Not having the economic means to purchase the needed medication was reported as a $15 \%$ monthly incidence. In addition, $28 \%$ stated not buying needed food in order to buy their medication. Credit card debt to purchase the medication also increased by $14 \%$ and $10 \%$ reported borrowing money from family and friends in order to buy the medications (Piette, Heisler, \& Wagner, 2004).

In 2012, West Virginia was ranked $47^{\text {th }}$ as one of the unhealthiest states in nation (WVDHHR, 2013). The ranking has changed from $43^{\text {rd }}$ in the nation in 2011(WVDHHR, 2013). 
Health determinants such as high incidence of sedentary lifestyle and obesity are two of the contributing factors that explain why diabetes prevalence is high in West Virginia. Sedentary lifestyle and obesity are also key factors that are associated with development of diabetes. In 2011 , the state's adult obesity rate increased from $32.4 \%$ to $33.8 \%$, accounting for 490,000 obese people in the state (WVDHHD, 2012). The state also has the second highest rating for physical inactivity, at a rate of $31.0 \%$, which translates to 450,000 of its adult citizens

(WVDHHR, 2012). In 2009, the northern West Virginia obesity rate was 29.9\%, accounting for 10,130 of its residents, with $28.4 \%$ of them being physically inactive (Robert Wood Johnson, 2012; WVDHHR, 2012).

\section{Values and Beliefs of the Population}

The Appalachian values and beliefs are central to the people in the northern panhandle of West Virginia. These beliefs include religion, strong family bonds, cohesiveness, friendship, health, and integrity. These important values have been passed down from many generations according to Coyne, Popescu, and Friend (2006). Huttlinger and Purnell (2008) also reported that at the onset of illness, health care is delayed. The people usually try self-care practices first. When this approach does not work, they then turn to family, friends, over-the-counter remedies, a local pharmacist, an emergency urgent care, and finally they will get to the primary health care provider. The cycle for obtaining services may include as many as ten different sources before they obtain primary health care (Huttlinger \& Purnell, 2008). Often by the time people reach the primary health care provider, the disease process has progressed. Frequently, as a consequence of delay of obtaining care, the persons with uncontrolled diabetes are not sent to a specialist or tertiary center in a timely manner. Unfortunately, due to their advanced disease and late access to advance care they still may end up with complications that may lead to disability and/or death 
(Huttlinger \& Purnell, 2008). This cycle seems to repeat itself, and people build distrust for the health care industry because of poor outcomes (Coyne et al., 2006). The high incidence of unhealthy lifestyles, obesity, and the delay of care all contribute to the increased prevalence of diabetes in the population.

\section{ADA Standards of Care and Patient Compliance}

The authors of the American Diabetes Association (ADA) Standards of Medical Care in Diabetes-2014 depict diabetes as a complex, chronic illness, which requires continuous and multifaceted care that goes beyond glycemic control. Ongoing patient self-management and support are essential to decrease multi-organ damage. The ADA diabetes standard of care (2014) is designed to guide providers, patients, and others such as insurance payers and researchers. The standards include recommendations on screening, diagnosing, and treating diabetes. In addition, many of the recommendations are cost effective strategies designed to improve patients' well-being and decrease complications.

The standards are not consistently being used in the care of people with diabetes (Clancy et. al, 2003, 2008; Gutierrez, Gimpel, Dallo, Foster, \& Ohagi, 2011; Sanchez, 2011). In West Virginia between 2009 and 2010, 67.5\% of adult patients over the age of 18 received an annual foot exam, $66.9 \%$ received an annual eye exam, $69.7 \%$ had their A1C checked more than two times a year, $67.9 \%$ reported daily self-monitoring of blood glucose, $44.6 \%$ ever attended a diabetes self-management class, and 59.1\% received an annual influenza vaccine (CDC Diabetes Report Card, 2012). In summary this data indicates that the standards of care are not being met.

Provider and patient adherence to treatment of diabetes remains problematic. Although providers are armed with advanced knowledge in the treatment of diabetes, they are still not consistently using the ADA standards of care and they are not implementing management tools 
such as EMR registries, meaningful use data, and system alerts. In addition, they are not consistently sending patients to diabetic educational programs. Patient adherence to care is critical to obtain positive outcomes. A 2008 systematic literature review of 139 studies reported that $59 \%$ of the patients with diabetes adhered with their medications greater than $80 \%$ of the time. They found that $41 \%$ of patients only take their medications $72 \%$ of the time or less. When noncompliant patients were compared with compliant ones, the latter were found to have improved medical outcomes (Cramer, Benedict, Muszbeck, Keskinaslan, \& Khan, 2008). Two of the strategies to improve adherence suggested by the authors were patient education and group support (Cramer et al., 2008). A second study showed that simplifying the medication regimen for patients that need to take multiple drugs by using fixed-dose drug preparation increases medication adherence in patients with chronic disease. The fixed dose combinations showed a reduction of medication noncompliance by as much as $24 \%$ to $26 \%$. (Bangalore, Kamalakkannan, Parkar, Messerli, \& 2007). Kombiglyze XR and Janumet XR are examples of a fixed dose medication. The advantage of the combination drugs like Kombiglyze XR or Janumet XR is that it allows the patient to have the benefits of two classes of medications (biguanides and DPP-4 inhibitor) with only having to take one dose. Patients with uncontrolled type II diabetes may require up to three or more medications (ADA, 2014; Scottish Intercollegiate Guidelines, 2010) which will present a challenge for patients to follow without proper coaching. One study indicates that patient empowerment with knowledge and social support has a positive impact on compliance with treatment regimens (LeRoy et al., 2014). Lack of adherence to lifestyle modifications and medication can be problematic. The unhealthy lifestyles and the lack of adherence can lead to micro vascular and macro vascular 
complications. Thus, complications of diabetes continue to be the seventh leading cause of death in the nation and the sixth leading cause of death in West Virginia (WVDHH, 2012).

\section{Health-Care Delivery System}

Some experts propose that the current one-to-one, patient-to-provider medical health delivery system will be unable to meet the needs of the growing number of patients with chronic illness due to the decrease in the number of providers and the increase of medical cost (Ridge, 2012). Most diabetic care is given by primary care providers, but diabetes care is often suboptimal due to providers frequently failing to intensify clinical management when $\mathrm{A} 1 \mathrm{C}$ is high (Kirkman, Williams, Carffrey, \& Marrero, 2002). Many times when the diabetes care involves multiple insulin injections, the patient is usually referred to an endocrinologist (Phillips et al.,2005; Mazze et al., 1994). At that point, access to care becomes a deeper problem because of the limited number of endocrinologists (Rizza et al., 2011).

The number of endocrinologists in the United States is decreasing while the demand continues to increase (Rizza et al, 2011). In northern West Virginia, there is currently a shortage of endocrinologists. The project was located is a small urban area in northern West Virginia. The area has one full-time endocrinologist and two nurse practitioners who see endocrinology patients. The waiting time for new patient appointments is more than three months. In the current full-time endocrinology office, $70 \%$ of the patients have diabetes. A descriptive study completed in 2009 found that endocrinologists provide high quality care and meet $80 \%$ of the diabetic guideline goals, indicating that patients receive high-quality care (Shah et al., 2009). Unfortunately, patients with diabetes in northern West Virginia have limited access to cost effective, high quality advanced diabetes care, which results in high rate of complications, increased medical cost, and increased morbidity and mortality. 
Shared medical appointments provides an alternative to the typical one-on-one, patientto-provider encounter (Sikon \& Bronson, 2010). There are six major advantages. First, SMA is an evidence-based method of delivering quality care that has all the elements of individual medical appointments including the one-on-one, patient-to-provider encounter. It has a broader scope on prevention, updating immunizations, and routine health maintenance. It also allows the provider to give better attention to patients' psychosocial issues (Noffsinger, Sawyer, \& Scott, 2003). Second, the SMA format approach enhances productivity and increases patient access. It allows the medical provider to see a group of 8 to 20 patients at the same time. It triples productivity as much as 4.5 hours of work in 1.5 hours (Brower, 2009). This can translate into a full-time physician FTE for every 12 SMA groups. Thus, the SMA format increases productivity and allows increased medical access to patients with chronic illnesses. Third, results show that patients and providers liked the SMA format by giving it high ratings (Thacker, Maxell, Saporito, \& Bronson, 2005; \& Beck et al., 1997). Fourth, the SMA patient group knowledge base increased, and patients achieved higher scores in quality-of-life measures. (Gutierrez,et al., 2011). Fifth, patients also benefited from receiving disease-management education and participant support (Sikon, \& Bronson, 2010). This is accomplished via an educational component that is designed to help patients improve unhealthy lifestyle behaviors via cognitive and behavior modification interventions that lead to increased problem solving and enhances coping techniques (Ridge, 2012). Sixth, evaluation studies in the literature show mostly positive outcomes. In conclusion, the SMA has shown improved glycated hemoglobin (A1C) control among diabetics (Housden, Wong, \& Dawes, 2013) and the patients with diabetes have improved outcomes (Edelman, McDuffie, Oddone, Gierisch, Nagi, Williams, 2112; Edelman, Gierisch, McDuffie, Oddone, Williams, 2014; Watts, Strauss, Pascuzzi, O'Day, Young, 2015). 


\section{Statement of the Problem}

Diabetes is a devastating progressive disease that if not managed properly leads to major organ damage and ultimately death. The prevalence in northern West Virginia is greater than in the nation as a whole. In the region, people with diabetes are at an increased risk of poor outcomes due to their unhealthy life styles, their values and belief systems, poor adherence, inconsistent use of the ADA standards of medical care, and decreased access to endocrinology providers. All of these factors are compounded by a health care delivery system that is unable to meet the needs of the increased population of persons with diabetes, leaving providers and patients unsatisfied. The end result is increased medical cost and increased morbidity and mortality.

\section{Purpose of the Project}

The purpose of this quality improvement project was to improve patient access to endocrinology care, improve adherence to the ADA standards of care, and improve patient and staff satisfaction with the health care delivery system via implementation of SMAs at an endocrinologist's office in northern West Virginia. This is an evidence-based health care delivery strategy that has improved patient access, allowing for more patients to be seen in less time (Bronson \& Maxwell, 2004), improved adherence to the ADA standards of care, improved patient outcomes, and improved patient and staff satisfaction with the health care delivery system

(Clancy et, al., 2003a, 2007b, 2008c; Dickman et al.,2005; Guiterrez et al., 2011; Sanchez, 2011; Wagner et al.,2001). The SMAs were implemented at an endocrinologist's office in northern West Virginia. Shared medical appointments were implemented by using the Chronic Care Model as a road map. The Chronic Care Model has six elements that fit well with SMA. These 
elements including the following: (1) organizational support, (2) delivery system design, (3) community resources, (4) patient responsibility, (5) clinical information systems, (6) decision support.

The quality improvement project included the following four specific objectives:

1. To increase patient access to an endocrinology office in northern West Virginia.

2. To improve adherence to the ADA standards of care.

3. To improve patient satisfaction after health care.

4. To improve staff satisfaction with care delivery.

\section{Significance of Proposed Project}

The shared medical appointment format is an evidence-based approach that has shown positive implications on the health-care delivery system by improving processes and achieving positive measurable outcomes. The objectives for this capstone were consistent with the SMA's positive outcomes documented in the literature. The SMA is a strategy, if used appropriately, improves patients' access and outcomes at the endocrinologist office in northern West Virginia.

The significance of the SMA quality-improvement project was demonstrated in the following: First, it improved access to endocrinology care in northern West Virginia for patients with diabetes. The SMA format allowed the provider to see an additional six patients in the same time frame. This was $100 \%$ increased efficiency. Second, the provider maintained adherence to the ADA standards of care and this was documented via the EMR's diabetic flow sheet. Research indicated that patients improved outcomes when the ADA standards are incorporated in the patient's care. Third, there was an expected increased patient satisfaction with the SMA format. The increased patient satisfaction was due to increased time in the medical visit to learn and address diabetic care concerns. Furthermore, there was an expected increased 
satisfaction with the SMA by the health-care providers. The increased satisfaction was due to improved efficiency and productivity. The group setting allowed the provider to have more time to address complex problems and improve the quality of care.

\section{Literature Review and Synthesis}

The PICOT (population, intervention, comparison, outcome and treatment) method was used to develop an appropriate question to be used for this literature review and quality improvement project. The PICOT question for this study is the following: Does the SMA format healthcare delivery system provide increased access to persons with diabetes, improved adherence to standards of care, and improved patient and staff satisfaction with the health-care delivery system. The population of interest is type I and type II adult patients with diabetes in the northern Appalachian region of West Virginia. The intervention to be used is SMA health-care delivery system. The comparison looked at the outcomes of one-on-one, patient-to-provider care as indicated at baseline (pre-SMA) and the outcome after the intervention (post-SMA). The treatment was the implementation of ADA clinical guidelines and standards through the SMA health-care delivery system.

The primary objective of the literature review was to analyze characteristics of SMA that have been tested in clinical trials with persons with diabetes. These objectives included the following: (1) to evaluate if SMA had a positive effect on access to care, (2) to evaluate if the SMA format increased adherence to the ADA standards of care. This included patient selfmanagement and changes in A1C, which are two facets of ADA standards of care that will be targeted in the SMA but not measured, (3) to determine patient and staff satisfaction with the SMA system, (4) to evaluate if the SMA format decreased medical cost. Although not one of the measurable objectives, cost containment will directly affect the success of this quality 
improvement project. The studies met either level one, level two, or level three grading classification requirements as outlined by the Agency for Healthcare Research and Quality.

The search method to locate optimum level of evidence for this PICOT question included an in-depth search of the CINAHL, Medline/ PUBMED, and the Cochrane Systematic Reviews. Limits were set on time between 2002 until May 2015, and only English language articles were used. Keywords used in the first search were "shared medical appointments." This yielded eight articles in CINAHL, 79 articles in PubMed, and five articles for Cochrane Library database. The search was narrowed to include key terms "diabetes shared medical visits." This yielded 31articles in CINAHL, 65 articles in PubMed and four articles in the Cochrane Library. The next term used in the search was "diabetic medical group visits". Eight articles were obtained in CINAHL, 82 articles in PubMed and no articles in the Cochrane Library. In addition, snowballing method was used to locate five more appropriate studies. Studies were excluded if they did not relate to the PICOT question; they needed to include diabetic share medical appointments as a health-care delivery system and articles needed to include a prescribing medical doctor or nurse practitioner as the health-care provider.

A total of twenty-one studies were initially identified via their titles, abstracts of the articles were obtained and only the articles where the abstracts met the inclusion criteria were obtained. This search resulted in 17 studies meeting the criteria for inclusion. Four of the seventeen studies are systemic reviews, and three of these completed a meta-analysis of the effectiveness of SMA and clinical outcomes. The remaining thirteen articles are randomized controlled trials, quasi-experimental studies, or nonexperimental studies. These remaining 13 studies were appraised for the six characteristic outcome measures of interest. These quality measures are the following: (1) increased patient access, (2) adherence to the ADA diabetic 
standards of care including biophysical outcome of A1C and self-monitoring, (3) patient satisfaction, (4) staff satisfaction and (5) decreased cost.

\section{Increased Access to Care}

Increased access to care was not an outcome evaluated by any of studies reviewed. Access to care may not be a problem because it is an established finding that SMA allows the provider to see more patients in less time with increased efficiency and improved outcomes (Noffsinger, Sawyer, \& Scott, 2003). The articles also did not address increase access in rural areas such a West Virginia. Furthermore, an adequate measure of access may not have been identified.

\section{ADA Diabetic Guidelines}

The use of the ADA guidelines aids to prevent devastating diabetic complications. These complications include both microvascular and macrovascular changes that lead to coronary artery disease, cerebral vascular accidents, end stage renal failure, neuropathy, blindness, and amputations (CDC 2011). The overall goal of SMA model is to improve patients with diabetes' outcomes. This is accomplished by screening, controlling, and managing the patient's diabetes. Clancy et al. $(2003,2008)$ reported improved compliance with ADA standards of care. Clancy et al. (2003) reported that the SMA group had a significant improvement in the use of the ADA standards. They used a mean total number of criteria to measure the outcomes, with SMA scoring $8.75 \pm 0.17$ compared to usual care score of $7.22 \pm 0.24$ in the control group $(\mathrm{p}=<$ 0.001 on a student's t test statistical analysis). They also completed a Wilcoxon's test on this data, and the outcome was also statistically significant in compliance with ADA standards of care $(\mathrm{p}<0.001)$ for the SMA compared to standard care. 
Gutierrez et al. (2011) compared the use of the ADA clinical standards of care indicators in patients participating in 36 SMAs against a control group of patients who received usual care. The indicators measured were the rates of influenza vaccine, microalbumin-creatinine ratio, complete lipid panel, foot examination, eye examination, aspirin use, and low density lipoprotein cholesterol level of less than $100 \mathrm{mg} / \mathrm{dL}$. All of these indicators were higher among in the SMAs group compared to usual care group. In the usual care group, the patients' influenza vaccine rate was significantly lower than the SMA with the usually care rate at $90 \%$ and SMA rate at $94 \%$. The same phenomenon was observed with foot examination in the usual care group which $61 \%$ compared to $84 \%$ with the SMA group.

Sanchez, (2011) collected data from 70 patients who received diabetes self management education (DSME) via SMA during the study. The outcomes data were also based on the ADA standards of care. This included A1C, blood pressure, lipid levels, (including LDL and triglycerides), urine collection for albumin measures, eye examination, use of aspirin, feet examination, and assessment of smoking. She found that more than $50 \%$ of the patients maintained blood pressure below 130/80. The ADA standards for lipid control were met; angiotensin receptors blocker medication was started as indicated for patients with positive urine albumin. Any patient without a previous eye exam in the last year was given referrals to an ophthalmologist, and aspirin was started on all patients if they were not allergic, and if they were over the age of 40 . They reported $100 \%$ of yearly A1C testing.

In addition, Sanchez (2012) compared her findings against the U.S. average data generated by the National Committee on Quality Assurance's (NCQA) Healthcare Effectiveness Data and Information Set (HEDIS) 2007. The A1C in the HEDIS quality indicator is set at 9\%; thus the $\mathrm{A} 1 \mathrm{C}$ of greater than $9 \%$ in the study was only $21 \%$ compared to $29 \%$ of diabetics in the 
U.S. in 2007 . Eye exam was also better at $66 \%$ compared to the U.S. average, of $53 \%$. In addition, the study showed a 97\% yearly LDL screening. Since, the LDL is not measured by HEDIS, the researchers were unable to make a comparison. But in the study the LDL value of less than 100 was $79 \%$. In regards to nephropathy, Sanchez reported a very low incidence of nephropathy of only $25 \%$ compared to the USA average of $80 \%$. All the outcomes quality indicators were better in the SMA group compared to the national indicators.

\section{Glycated Hemoglobin (A1C) Outcomes}

The $\mathrm{A} 1 \mathrm{C}$ outcome measures in the literature are mixed, although there are more positive changes than negative outcomes. For example, two studies reported significant change in biophysical marker (Gutierrez, et al., 2011; Kirsh, et al. 2007). Six studies reported positive effects as a result of SMA intervention in comparison to usual care (Clancy, et al. 2003; Dickman, et al., 2012; Dontje, \& Forrest 2011; Edelman, McDuffiew, Oddone, Gierisch, \& Williams, 2010; Ridge, T. 2012; Sanchez, 2011). Clancy, Yeager, Huang, \& Magruder, (2007); Mallow, Theeke, Whetsel. Barnes, (2013); Trento et al., (2004); and Wagner, et al. (2001) reported that the A1C either remained stable or no change was observed. Mallow et al. (2013) study was with uninsured patients in North Central West Virginia. The patients in the intervention arm had poor attendance to the SMA and due to this poor patient turnout, there were no changes in the outcomes. The results were not homogeneous among the studies evaluated. As indicated above the study in North Central West Virginia showed no change in the A1C but all the other studies all indicated improvement or maintaining A1C in the SMA group in contrast to usual care where the $\mathrm{A} 1 \mathrm{C}$ increased.

The four systematic reviews by Edelman et al. (2012); Housden et al., (2013); Quinones, Richardson, Freeman, O’Neil, \& Kansagara (2012); and Simmons, \& Kapustin, (2011) all 
reported a reduction of the $\mathrm{A} 1 \mathrm{C}$ as a result of SMA intervention with patients with diabetes when compared to usual care; the rate of reduction is varied among the four studies. Housden et al. (2013) reported that the A1C improvement was affected by the duration of treatment. Thus, they found that the longer the duration of the SMA appointments, the greater the improvement in the A1C. In contrast, Quinones et al. (2012) reported that SMA improvement on the A1C only had a modest improvement compared to usual care (mean difference A1C 0.27\%. 95\% Cl-0.44). Quinones et al. (2012) agreed with Housden et al. (2013) that the longer the time period of SMA the more noticeable effect on the A1C. The studies reviewed by Simmons et al. (2011) also showed mixed results in $\mathrm{A} 1 \mathrm{C}$ improvement ranging from significant to just maintaining the A1C at 7.4\%. Maintaining a stable A1C over a period of two years is considered an improvement when compared to A1C for patients in usual care that normally results in an increase over a twoyear time period (Trendo et al., 2001).

Edelman et al. (2012) and Quinones et al. (2012) explained that the difference in the rate of reduction of $\mathrm{A} 1 \mathrm{C}$ in the studies may be due to the heterogeneity among them, which leads to decreased confidence in the results. It is interesting that in a multivariate meta-regression analysis of covariates, the variations in $\mathrm{A} 1 \mathrm{C}$ results were found to be independently related to the duration of SMA, the quality of the study, or the time of the publication (Quinones et al., 2012).

\section{Evidence of Improved Self-Monitoring}

Eight studies addressed self-monitoring as an outcome of SMA. The eight studies include Clancy et al. (2008); Dontje and Forrest (2011); Edelman et al. (2010); Edelman et al. (2012); Housden et al. (2013); Quinones et al. (2012); Simmons and Kapustin (2011); and Trento et al (2002). Clancy et al. (2008) reported that patients had improved perception of diabetic care. Although this is not self-monitoring, Clancy et al. (2008) believe that one needs to understand 
the disease process before changing behaviors. In the Dontje and Forrest (2011) study, participants reported improved self-management of their diabetes as well as improved communication in both SMA group and the usual care group. They stated that this was a direct result of increased use of the ADA standards of care. In the Edelman et al. (2010) study, the participants in the SMA group reported having increased medication adherence as result of the intervention. But, Trento et al. (2002) findings were more impressive; they observed improved health behaviors among the patients that participated in the SMA as well. These changes included improved problem-solving skills, patient self-monitoring, and quality of life. The increased quality of life was an important finding not found in other studies. In addition, Trento and Quinones reported decreased hypoglycemic episodes (Trento et. al., 2002; Quinones et al., 2012). Simmons and Kapustin (2011) and Housden et al. (2013) concluded that patients' increased self-monitoring was a result of the SMA. Simmons and Kapustin (2011) stressed that SMA format augmented patients' self-care behaviors by improving dietary and medication compliance. They explained that in order for patients to achieve improved self-monitoring, the providers need to have a plan of care with specific objectives or goals. These goals need to be outlined and discussed with the patients at the onset of the SMA. Quinones et al. (2012) also demonstrated improved self-monitoring as a direct effect of skill training as an intervention on self-management rather than the traditional didactic teaching style.

\section{Patient and Staff Satisfaction}

Patient and staff satisfaction was analyzed in four studies (Clancy et al., 2007; Dickman et al., 2012; Trento et al., 2005; and Wagner et al., 2001). Clancy et al. (2007) indicated significant improvement in patients' outlook on their health care services, culture proficiency, and in their trust with their medical team. Dickman et al. (2011) reported 95\% of the patients 
rated the SMA experience as excellent or as very good. They also stated that participants reported improved health after the intervention. All the participants reported that they would participate again in the SMA in addition to encouraging family and friends to enroll in future SMAs. These results may be biased since the clinic was a free clinic, and the patients' responses may reflect their gratefulness for the care received. Trento et al. (2005) also reported patient satisfaction with the SMA format. Wagner et al. (2001) reported similar findings: Pre-SMA patient satisfaction was $50 \%$, Post-SMA patient satisfaction went up to $60 \%$ compared to usual care, which declined from $57 \%$ to $53 \%$. Thus, patients were very satisfied with the SMA format compared to the usual care format.

In another systematic review, Simmons and Kapustin (2011) reported that all the studies they reviewed indicated increased patient satisfaction with the SMA. It is unclear if this satisfaction was a result of the group dynamics or the individual characteristics of the providers that offered the SMA. Motivational interviewing techniques may be another variable that may contribute to patient satisfaction. Edelman et al. (2012) reported that only two of the studies they reviewed reported patient satisfaction with the SMA format, and both of the studies showed great satisfaction with the SMA format compared to the usual care format.

\section{The Economic Benefits of SMA}

The economic benefits of the SMA were examined in Clancy et al. (2007); Clancy et al. (2008); Trento et al. (2001) and Wagner et al. (2001). In addition, the financial benefits of the SMA format were also examined by two of the systematic reviews, Edelman et al. (2012), and Simmons and Kapustin (2011).

Clancy et al. (2007) reported significantly increased financial burdens for patients in the SMA intervention compared to usual care over a six months period. The increased cost was in 
outpatient visits, inpatient admissions, and emergency room visits. They reported that in a sixmonth period patient costs for the SMA participant was $\$ 2,886$ compared to $\$ 1,490$ for the patients in the usual care in the control group. They did explain that one reason for the increased cost was due to greater inpatient admission costs. Nevertheless, in a second study Clancy et al. (2008) found that in a year's time total, charges were significantly less for the intervention group in the SMA. The overall cost per patient in the SMA group was $\$ 5,869$ compared to the usual care group per patient cost of $\$ 8,412,(\mathrm{P}<0.05)$. Wagner et al. (2001) confirmed these positive cost-effective advantages resulting from the SMA health-care delivery system. Advantages were also observed in decreased emergency room visits, decreased in-house hospital admissions, decreased specialty visits, and decreased disability days. The study size was large and included 714 randomized participants over 14 different health-care settings for periods of longer than one year.

The two systemic reviews had mixed findings. Simmons and Kapustin (2011) reported increased provider productivity of patient visits per day from an average of 20.17 to 31.55 . They also calculated increased reimbursement rate of $\$ 737.20$ by using standard Medicare rate reimbursement for level 99214 office visit. Edelman et al. (2012) reported mixed findings similar to those above. For example, in three of the five studies analyzed, the inpatient admission rates were lower within the intervention group. Only one study showed significantly lower admission rates. One study showed no significant decrease for inpatient admission rates $(16.9 \%$ compared to $21.0 \%, \mathrm{p}=0.10)$. ER visits were also analyzed with these same five studies. 
The findings were also mixed. Two studies indicated significantly lower ER admission, whereas three studies showed no difference in ER visits between SMA and usual care participants.

In conclusion, this synthesis of the literature examined the six characteristic outcomes of interest and illustrated for the most part positive outcomes as a result of SMA health-care delivery system. This indicates that the SMA format is an evidence-based health care delivery.

\section{Theoretical Framework}

The quality-improvement project implemented the SMA health-care delivery system for adult patients with diabetes at an endocrinology clinic in Northern West Virginia. The plan used the Chronic Care Model as a road map to develop and implement the SMA format. The Chronic Care Model has six principles that fit well with this care delivery system. The model is a proactive evidence-based model intended to change the current health care delivery system for patients with chronic illness such as diabetes.

History of the Model. Modern medicine and research has led to many effective treatment plans to address chronic health problems, yet research shows that many individuals afflicted with chronic illnesses still don't receive the care needed (IOM, 2001). As the baby boomers are getting older, and the prevalence of chronic health illnesses continues to increase, these patients are facing many barriers in receiving cost-effective quality care under the current health-care system (Wagner, Austin, Davis, Hindmarch, Schaerfer, \& Bonomi 2001). The main reason for the lack of quality care is due in part to the fact that the health-care system is intended for the treatment of acute illnesses and it creates a mismatch for patients with chronic health illnesses. The core problem is not lack of knowledge on the provider side but system failure (IOM, 2001). The system lacks organizational tools to deal with the increased number of complexities of today's science and technology. The acute care model often does not meet the 
patients' medical needs, psychological, and informational support that is needed to address all the requirements of patients with chronic health illnesses (Wagner et al. 2001). These illnesses account for as much as $59 \%$ of all deaths and $46 \%$ of the world wide diseases (Coleman, Austin, Brach, \& Wagner, 2009). The existing structure is designed to address acute problems or injuries, thus not equipped to deal with chronic care issues that will allow the patient to be the primary driver of his/her care. A change in the delivery system that provides excellent quality is needed.

The CCM was initially developed as a consequence of an in-depth review of evidencebased interventions for chronically ill patients (Render et al., 2002). The researchers found four multifactor elements that supported the largest positive change in health care delivery that yielded measurable positive health outcomes. The initial four strategies included the following: (1) expanding the caregivers' proficiency and aptitude; (2) coaching and encouraging patients; (3) using a multidisciplinary approach by using effective teams of health care delivery; and (4) utilization of electronic medical systems.

The chronic care model is intended to improve patient outcomes by transforming the health-care delivery system via a six evidence-based principles of care. These elements including the following

1. Organizational support

2. Delivery system design

3. Community Resources/ Policies

4. Self-management

5. Clinical information systems

6. Decision support 
In using these six principles, the health-care team can change the current acute reactive model of care to one that is proactive, planned, and population based. See Appendix A for model with the breakdown of each of the six elements.

The six elements of the chronic care model was used as the road map to guide the SMA at the endocrinology office in Ohio County. This was accomplished by taking each element of the model and applying it to the strategic plan.

Organizational Support/ Health Systems. The health system and organizational support is the fir element of the model. This element deals with the establishment of a culture that promotes safe and high quality care. This is accomplished by having support at all levels of the organization including all levels of leadership. The organization also needs to promote strategies to improve health care and maintaining a culture of open communication to improve health-care delivery. It provides an environment where errors are handled in an open and systematic manner to improve quality of care. In addition, it needs to promote the development of agreements that support care coordination within and across the system (Wagner et al., 2001; Group Health Research Institute [GHRI], 2014).

Delivery System Design. Delivery system design is the second element of the model. It deals with assuring effective, efficient clinical care and self-management support. This element requires that health-care provider' roles, responsibilities, and job descriptions are well defined. It also requires that planned interventions be evidence-based providing clinical management services for the complex patients. Furthermore, it requires culturally appropriate care and regular patient follow-up (Wagner et al., 2001; GHRI, 2014).

Community Resources and Policies. The third element addresses the community resources and policies. In this element of the model is to establish a relationship with 
community-based resources in order to meet the health-care management needs of patients and to avoid duplication of services. It also provides a framework to develop and implement policies to improve patient care (Wagner et al., 2001; GHRI, 2014).

Self-Management. The self-management element is the fourth element of the model. It requires empowering patients by giving them the tools needed to take control of their own disease process (Wagner et al., 2001). The author believes that patients that utilized appropriate self-management tools to manage their diabetes have improved outcomes.

Decision Support. Decision support is the fifth element of the model. This element promotes medical care that is consistent with evidence-based medicine and takes into account the patients' preferences. It calls for the evidenced-based guidelines to be embedded in diseasebased registries, and electronic medical records reminders to promote compliance at the same time that it generates meaningful use outcome data. The clinical guidelines and medical information is imperative to be shared with patients to promote their involvement in the care. In addition, providers should use proven teaching methods to educate the patients and to involve specialist expertise when possible. This element also advocates for providers to receive ongoing continuing education to assure up-to-date clinical knowledge. It also promotes guidelines to be integrated with timely reminders, feedback, standing orders and other methods that will enhance the clinical decision process (Wagner et al., 2001; GHRI, 2014).

Clinical Information Systems. The objective of the clinical information systems element is to enhance quality care by having access to key data for the individual patient and for a population of patients. The EMR system augments the quality of care by giving timely reminders, by allowing individualized planned care, and by sharing of information with patients 
and providers, which allows the practice to monitor its performance (Wagner et al., 2001; GHRI, 2014).

\section{Project}

\section{Description and Design}

A strategic plan to implement the SMA included four phases, a preplanning phase; a planning phase, an implementation phase, and an evaluation phase. A budget was also included in this plan, as well as four measurable objects that determined if the quality improvement project had a positive impact on the health-care delivery system. Key stakeholders were recruited to help with the SMA. The nurse leader was vital as the change champion, as the knowledgeable practitioner and as the key person responsible for implementing the quality improvement intervention.

Preplanning Phase. This phase included the following key elements. The nurse leader obtained IRB approval from The West Virginia IRB committee. The time line, budget, work plan and confidentially form that allowed compliance with Health Insurance Portability and Accountability Act of 1996 (HIPAA). See Appendix A for copy of the HIPAA form. The plan solicited key stakeholders to help carry out the SMA project.

The stakeholders' roles were defined at the onset of preplanning phase, engagement of the stakeholders early in the process was vital to assure a variety of perspectives that enhanced the quality-improvement project. It helped secure buy-in from key decision makers. Engagement also fostered transparency among the key members of the team, as well as helped expand the capacity of this quality-improvement project and future efforts. The stakeholders' involvement also helped to empower community members, increased public awareness, and improved coordination of the quality-improvement effort. 
The Stakeholders consisted of three key groups: an advisory group, a SMA core intervention team, and community partners group. Initially the nurse leader contacted the stakeholders to solicit support. The advisory group was made up of key administrators, a provider, and information system specialist, and a patient. They met as needed and no more than once a month during the duration of the SMA improvement project. The advisory group was contacted by the nurse leader the week before the meetings and an agenda for the meetings was distributed via email. The SMA core intervention team was made up of key staff personnel that meet weekly in a predetermined time slot on Wednesdays. Prescheduling assured that no other meetings, such as pharmaceutical drug representative lunches, were schedule at this time. The intervention team meetings were opened to the other stakeholders, but they were not required to attend unless scheduled a week prior to the meeting. The community partners were made up of key experts in health-care field and representatives of community agencies. They did not need to meet once their support was obtained. Communication method between the nurse leader and the stakeholders included email updates, phone calls, and face-to-face meetings as needed during the four phases of the intervention.

Planning Phase. Eight steps were included in the planning phase. First, the patient selection criteria were accomplished by following the guideline selection criteria form. Second, these patients also had an $\mathrm{A} 1 \mathrm{C}$ of $8 \%$ or greater. The level was drawn within the last month prior to the beginning of first SMA. Third, patient recruitment took place. The following process was used for recruitment purposes:

a. The EMR system was utilized to identify patients with a $\mathrm{A} 1 \mathrm{C}$ of $8 \%$ or greater that was less than one-month old. 
b. 100 letters of invitation were mailed to current patients with elevated A1C (see Appendix B for letter of invitation).

c. An informational flyer was posted in waiting rooms and exam rooms (see Appendix C for SMA flyer).

d. During regular office visits patients with elevated A1C were recruited.

Fourth, as patients were identified they were scheduled for all four appointments. They also received reminder calls the day prior to the SMA. Fifth, educational materials and supplies needed for the SMA were ordered. Sixth, the day prior to SMA the nurse practitioner reviewed medical records of the participants and set reminders for labs, tests, procedures or referrals that was needed. Seventh, the day prior to the SMA, the staff made sure the conference room was set up appropriately, tasks that include making sure the power point and projector was in working condition, that name tags and educational material packages were ready for the meeting as well as the light snack for the meeting is ordered.

Implementation Phase. In the implementation phase, initially two cohort groups were scheduled. Each had a total of 4 or more sessions, each session a month apart. The sessions were 120 minutes long. Each SMA cohort had a total of 12 to 15 patients. A 12 to 15 patient cohort was a feasible number that the staff could handle. This number of patients is in line with the SMA literature reviewed. In order to successfully complete this improvement project, each cohort group needed to have a minimum of 10 patients completing all four sessions, assuring a minimum of 20 patients. In order to assure this number of patients, the following was implemented: if three or more patients missed a meeting, a makeup session was offered to give these patients an opportunity to catch up with their group. If the makeup session was not possible and the number of patients fell below 20, new patients that met the A1C's inclusion criteria of 
$8 \%$ or greater were invited to participate. If patients dropped out of the SMA or if they attended less than two appointments, their information was not included in the evaluation phase. But their medical visit remained in their medical record. In each SMA cohort, the patients were divided into two groups (Group1 and Group 2), giving each group a 90-minute appointment time slot (see Appendix D for patient flow diagram). All patients were asked to report 10 minutes prior to their scheduled start time. Patients in Group 1 were scheduled in the first 30 minutes. Patients in group 2 were scheduled to report ten minutes before the educational session began. First, the patients were pre-registered in order to improve fluidity of the process. Patients and significant others signed the pre-registration form and signed the confidentiality forms. At this time the staff also downloaded the glucometers or insulin pumps. Once registration was completed, patients and significant others were asked to report to the conference room. The patients were given educational packages including the patients' personal medical information and their current medication list. Vitals, review of systems, and medication reconciliation was completed and recorded by the nurse while the nurse practitioner completes one-on-one physical exams in the same room behind a screen and later used an adjacent exam room. Once all the exams were completed, the nurse practitioner returned to the conference room. At the end of the first thirty minutes, once Group 2 was registered and settled in the conference room the educational session started.

The educational session was sixty minutes long and it was divided into two parts. The first thirty minutes was for the guest speaker and the second half was used to teach patient selfmanagement strategies. A total of four expert speakers were schedule a month apart to present the following four topics: (1) diabetes and nerve damage, (2) diabetes and eye complications, (3) diabetes and kidney complications, and (4) diabetes and cardiac complications. Reminder calls 
to the individual speakers were made the week of the SMA. Some of the presentations were videotaped to be used in future SMA sessions, since these experts may not be available for future SMA sessions.

The second half to the educational session was used to teach patient self-management strategies. The SMA intervention team used the Novo Nordisk program materials named Quality Diabetes Measures Kit. This kit follows the ADA diabetic guidelines. This diabetes education program kit was free of charge. Patient self-management is one facet of ADA Standards of Care and of the four objectives for this SMA change project. This was accomplished by allowing the patients to set realistic goals and by reinforcing adherence to medication, to exercise, to follow an ADA meal plan, and to test their blood glucose. The patients were asked to keep journals of these behaviors and were asked to bring their blood glucose meters to all the SMA for the staff to download at each visit. Positive health behavior strategies were reinforced via teaching techniques during the group medical meetings. The SMA allows for a natural support group to be built among the patients, and patients reported that this group support did enhance their compliance. It was also enhanced with specific patient-led health topics that was discussed during the group meetings. Motivational strategies such as motivational interviewing was utilized during the educational sessions. The SMA also included strategies such as shared decision making; the nurse leader guided the patient to make changes by allowing the patient to set his or her own goals. The patients were encouraged to make changes one step at a time. A personalized care plan was used; this walks the patient through a series of questions that allowed each patient to identify his or her concerns/ problems with their diabetes.

In the first SMA after the introduction to the program, the educational material included a care plan that was used and developed during all four SMA sections. The care plan included a 
shared decision plan, a diabetic medications plan, a healthy eating plan, a physical activity plan, and a plan for checking blood sugars. Each SMA educational session was focused on one or two of these major topics and used the care plan to individualize each patient's plan. The topic for the first session was on self-management. A ten-minute presentation on this topic was presented and the patients were asked to discuss how they usually accomplish their self-management. The session also focused on the first set of questions in the care plan. The questions included the following;

- What is my biggest concern about my diabetes?

- What do I want to achieve?

- What kind of support do I need to get there?

The section also included information on the importance of maintaining an A1C below $7.0 \%$. The brochure Understand Your A1C was used.

The second SMA education session focused on diabetes medication. A short ten-minute presentation on current medication was presented. The patients were allowed to discuss their concerns about their own medications. They also focused on questions in the care plan under the section label, My Diabetes Medicine Plan. The questions in the care plan included the following:

- What is my plan?

- What is my greatest challenge?

- How can I succeed?

The patients were also given handouts on diabetes medication including, Starting $A$ GLP-1 Receptor Agonist, Starting Long-Acting Insulin, and Starting Mealtime Insulin. 
The third SMA education session focused on healthy eating and exercise. A short tenminute presentation on healthy eating and exercise was given. The patients were allowed to discuss their concerns about their diets and exercise. They also focused in the care plan under the section label, My Healthy Eating Plan and My Physical Activity Plan. The questions in the care plan included the following:

- What is my plan?

- What is my greatest challenge?

- How can I succeed?

The patients were also given information and handouts on planning healthy meals and physical activities.

The fourth SMA education session focused on blood glucose monitoring and foot care. A short ten-minute presentation on at-home blood glucose monitoring and foot care was given. The patients were allowed to discuss their concerns about their blood glucose monitoring and foot care. They focused on questions in the care plan under the section label, My Plan for Checking Blood Sugar. The questions in the care plan include the following:

- What is my plan?

- What is my greatest challenge?

- How can I succeed?

The patients were also given information and handouts on the importance of knowing their numbers. In addition, they received a foot care sheet that shows tips for patients to take care of their feet. They were also instructed on how to test for loss of foot sensitivity. They were given monofilament cards with written instruction for foot screen test. 
Any other material needed was obtained via The American Association Diabetes

Education and was used for the DSME. This was important to assure that current standards of care were followed and materials were culturally relevant. The goal was to offer patients with diabetes culturally competent diabetes education to assist them in learning self-management skills that would help them to achieve better quality of life via improved blood glucose control and improved lifestyle behaviors that should result in positive medical outcomes.

Billing for the SMA was done through the regular ICD- 9, ICD-10, and CPT medical billing codes used by the care providers for the medical encounter. The nurse leader and the director of the clinic also tracked denials of any claims and the reasons for the denials and the results of the appeal process if needed.

The evaluation phase was accomplished by measuring the four objectives of the quality improvement project as described below in the evaluation plan section.

\section{Theoretical Framework and the Quality Improvement Project}

The six elements of the chronic care model were used to guide the implementation of the quality improvement project. In the first element of the model, organizational support, leadership at all levels provides a mechanism for improvement of health-care delivery such a SMA quality improvement project (Wagner et al., 2001; GHRI, 2014). The organization's mission statement and their quality improvement management plan mirrors the goals of the chronic care model. In order to implement the SMA the organization needed to have the appropriately trained personnel and the appropriate resources. The organization has the appropriate personnel for implementation of SMA in the endocrinology office. In addition, the organization allowed time for the endocrinology staff to implement the SMA. Furthermore, the organization also allowed a 
multidisciplinary team to participate in the SMA, which enhanced the project. In addition to the above resources, the organization has the infrastructure to carry out the SMA.

The delivery system design was the second element of the chronic care model; it promotes an effective, efficient clinical care, and self-management support. This element also required those health-care providers' roles, responsibilities, and job descriptions to be defined. In addition, it also required that planned interventions and clinical management services for complex patients are evidence-based. Furthermore, it required culturally appropriate care and regular patient follow-up (Wagner et al., 2001; GHRI, 2014). This element supported the quality improvement strategic plan in the following five ways. First, the SMA is an evidence-based health care delivery system that has been used in other centers with complex patients including the diabetic patient. Second, the SMA plan included defined roles and responsibilities for the staff and stakeholders. The plan also included a staff responsibility worksheet that was filled out for each SMA. This worksheet listed activities that need to be completed during the SMA process assuring that the providers address the ADA quality measures. Third, the diabetic flow sheet with the embedded ADA guidelines also served to document that the individual patients met the required evidence-based guidelines. Fourth, scheduling weekly staff meetings with the core intervention team allowed the members to make changes as needed, assured the SMA progressed as planned. The key stakeholders were also involved in the process. Fifth, the educational sessions on self-management and the use of individualized diabetic care plans also met the goal of this element.

Community resources/ policies is the third element of chronic care model. It identifies and mobilizes community-based resources to help meet health-care management needs of patients (Wagner et al., 2001; GHRI, 2014). This element also supported implementation of the 
SMA in the following three ways: (1) Advertising via flyers were posted in exam rooms and waiting areas, (2) calling on community experts, like the retina specialist, nephrologists, cardiologist, neurologist, exercise physiologist, and nutritionist to speak on various topics of interest during the SMA, and (3) partnering with the Wellness Center. All the above community resources were needed to carry out the quality improvement project and to help assure the success of the SMA.

Self-management and support is the fourth element of the chronic care model. In this element providers need to provide methods and opportunities for patients to be empowered and prepared to manage their health conditions (Wagner et al., 2001; GHRI, 2014). This element mirrors objective number three of the quality improvement project, diabetic self-management. This was accomplished by the following five ways. First, the multidisciplinary guest speakers addressed major diabetic complications and ways to prevent them. The patients learn and may take action as a result of these motivational speakers and the patients may decrease their risky behaviors that lead to these major complications of diabetes. Second, patient self-management was enhanced with the tools and information utilized during the group meetings. Third, the health topics used during the second half of the educational session also taught, motivated, and empowered patients to take control and better self-manage their diabetes. Fourth, the self-led discussions during the educational sessions enhanced self-management. Fifth, motivational interviewing, teaching techniques, and the individualized care plans used during the SMA also empowered the patient to make changes that are realistic and sustainable.

The fifth element of the chronic care model was the use of clinical information systems. The objective of this element is to enhance quality care by having access to key data for the individual patient and for a population of patients. The EMR system augments the quality of care 
by giving timely reminders, by allowing individualized planned care, and by sharing of information with patients and providers, which allows the practice to monitor its performance (Wagner et al., 2001; GHRI, 2014). The current Sunrise EMR system in the endocrinologist office of interest has the capability to do all of the above. The EMR system was instrumental in allowing the nurse leader to accomplish the measurable objectives outline in the proposal. The system also allowed providers access to the entire patient's medical information that is given within the system. It alerts the provider when certain studies are completed and ready to be read. It also allows the providers to generate consultations and referrals to other providers with the clinical note embedded in the letter. The system also generates letters to patients with normal or abnormal values. The EMR system has a diabetes care template note that allows documentation of individualized patient care. The system also includes user-friendly features that enhance the quality of care that helps to increase efficiencies. In addition, it has the ability to generate meaningful use data which allowed the practice to monitor its performance.

The sixth element of the chronic care model is the decision support element. This element promotes medical care that is consistent with evidence-based medicine and takes into account the patients' preference. It calls for the evidenced-based guidelines to be embedded in disease based registries, and electronic medical records reminders to promote compliance at the same time that it generates meaningful use outcome data. It is imperative that the guidelines and medical information be shared with the patients to promote their involvement in the care. In addition, providers should use proven teaching methods to educate the patients and to involve specialist expertise when possible (Wagner et al., 2001; GHRI, 2014). This element also advocates for providers to receive ongoing continuing education to assure up-to-date clinical 
knowledge. They promote guidelines to be integrated with timely reminders, feedback, standing orders and other methods that will enhance the clinical decision process.

The SMA proposal met the requirements of this element in the following three ways. First, the electronic medical system (EMR) used by the office already had a diabetic template for the clinical note that is currently being used in the endocrinology office. It also had a diabetic flow sheet with the ADA guidelines embedded. The EMR system has many reminders and alerts to help the provider identify gaps in care. Currently the system alerts the provider when labs are posted and need to be evaluated. There are also many alerts with the use of e-scribing; for example, if the patient is allergic to specific medication, the system alerts the provider. It also alerts the provider when there are potential medication interactions. Meaningful use data is also generated and reported on a monthly basis.

Second, patient engagement takes place by open communication between the provider and the patient. The patients are encouraged to write down questions and concerns before every office visit. The patient received feedback during the SMA and was given a hard copy of any laboratory work, other studies, and a hard copy of the summary office visit. The results of the lab work can also be tracked and graphed giving the patient and the provider a visual view of lab trends and core measures. The patient was also encouraged to be an active participant in the SMA group meetings. Furthermore, the hospital was also in the process of enhancing the online capabilities to allow patients to have access to their medical records, make their appointments, as well as contacting the provider via the EMR system with concerns.

Third, administration values and promotes continuous educational credit for all of its providers. This is evident in the budget. Administrations allocates money for the providers to 
take paid time off and the providers are given a yearly monetary allowance to stay updated with evidence based programs.

\section{Feasibility Analysis}

The strengths, weaknesses, opportunities, and threat (SWOT) analysis was conducted for this quality improvement project. The strengths included the following seven important elements. First, the practice uses evidence based ADA diabetes clinical guideline in their diabetic flow sheet. Second, the practice has an ideal meeting room to run the SMA meetings. Third, the practice has a well-trained staff. Fourth, the practice has an established electronic medical system which the staff are proficient users. Fifth, the Wagner's chronic care mode is a proven model used in other SMA. Sixth, the current staff and patients reported satisfaction with the care they received and the staff reported satisfaction with their current jobs. Seventh, the organization is supported of the quality improvement project.

The weaknesses included five elements. First, the SMA has not been tested in an endocrinology setting. Second, participants needed to have uncontrolled diabetes with an A1C of 8 or greater and they needed to volunteer to participate in the SMA. Third, the participants needed to pay a co-payment and their insurance were also billed for the visit. Fourth, the patients needed to agree to four or sessions of ninety minutes long. Fifth, noncompliant patients may prolong completion of the project.

The SWOT analysis also included ten opportunities. First the endocrinologist at the practice of interest is the only full time endocrinologist in the county of interest, there is another part time endocrinologist and one that just retired. Second, there is another full time endocrinologist in the neighboring county which is 45 minutes away but he is ready to retire. Third, Implementation of the SMA decreased the waiting time for new referrals to be accepted. Fourth, the SMA is a new 
innovated method to deliver quality health care. Fifth, used tested teaching resources from Novo Nordisk that includes the AADE guidelines for quality diabetic measures. Sixth, The SMA participants may decrease their hospital admissions. Seventh, the participants may decrease early morbidity and mortality. Eighth, implementation of the SMA may increase medical and social support systems for patients with diabetes in area of interest. Ninth, the SMA format may increase office productivity for the office of interest. Tenth, adding the SMA format may increase available services in the northern, West Virginia area.

In addition, the SWOT analysis included three threats. These included the following. First, the closing of the coal mines and steel mills may negatively impact the economic in northern, West Virginia area causing patients to lose their insurances. Decreased insured patients may decrease the number of patients willing to participate in the SMA. Second, the impact of the new health care reform may have a potential budgetary cuts of supported positions due to decrease rate of reimbursement for current services. Third, participants may drop out of the SMA program and may need to add additional meetings to complete the SMA evaluation process.

\section{Resources}

The nurse leader identified the following resources for the quality improvement project to be successful. First, the West Virginia School of Nursing Capstone Committee was instrumental guiding the nurse leader in developing, implementing, and evaluating the quality improvement project. Second, the West Virginia Institutional Review Board (IRB) Committee was instrumental for assuring the quality improvement project was in compliance with their regulations to protect all the patients that participated in the SMA. Third, buy in from the SMA core intervention team, stakeholders, and key community resources was essential to facilitate the quality improvement project. Fourth, other resources that were needed to implement the quality 
improvement project was the educational materials from Novo Nordisk. The flyers were designed and produced by the nurse leader. The conference room was an in-kind donation from the clinic and it was reserved for the SMA. The SMA participants were provided with a light snack. The cost was covered as an in-kind donation from the clinic. Overall, the final cost for the quality improvement project was minimal.

The nurse leader and the core intervention team also used the following resources as tools to assure the quality improvement project was on target. First, a check list worksheet that defined activities that the members of the core team need to complete was used. The worksheet included pre-appointment activities, activities during every appointment, and activities after the visits. Second, the current diabetic flow sheet was used in the SMA since it has the ADA diabetic guidelines imbedded, and it allowed the provider to document adherence to the ADA standards (See appendix E). This diabetic flow sheet was essential for measuring compliance with ADA guidelines, which is one of the outcomes of the study. In addition, a patient's educational attendance checklist was also used. This checklist allowed the provider to keep track of the educational sessions the patient completed. Furthermore, every patient was asked to provide a copy of their yearly comprehensive dilated eye examine for their diabetic record. If they do not have one, they will be referred to a retina specialist. At the end of the four SMAs, all the patients received a certificate of completion and their significant others will also have received a certificate that recognizes them for the support they gave to their diabetic family member or friend.

\section{Personnel}

The office has the appropriately trained staff which includes an endocrinologist; two nurse practitioners, one who is a dedicated diabetic nurse practitioner (nurse leader, DNP 
student); a licensed practical nurse; three medical assistants; and two front office support staff. Other key members of the organization that were needed was the director of the clinic, a member of the wellness center (nutritionist/exercise physiologist), and an information specialist from the information technology department. The endocrinologist, the director of the clinic, an information specialist and one of the nurse practitioners (not the nurse leader) will make up the advisory group. The SMA core intervention team was made up of the nurse leader, one of the medical assistants, the practical nurse, and one of the front office staff.

Additional stakeholders that played a key role in the implementation and success of the SMA included the following; The Information System department who help with the electronic medical system. In addition to the stakeholders, key community partnerships needed to be established to help promote the program, identify and mobilize potential patients, and assure continuity of the SMA. Partnerships are already established with the family practice offices that refer patients to the endocrinology office, Nephrology Associates, Dr. Leeper' Retina specialists, with Wheeling Hospital Wellness.

\section{Technology}

Vital aspects of the quality improvement project included the use of computers, printers, and the current Sunrise Electronic Medical Record (EMR) which was essential in maintaining cohesiveness of the SMA. First, as stated above the current Sunrise EMR system in the endocrinologist office has the ADA standards of care embedded in the diabetic flow sheet. It also allowed the provider to track the patients' medical studies such as lab, radiology, and other studies. In addition, it allowed providers access to the entire patient's medical information that has been delivered within the system. It alerts the provider when certain studies are completed and are ready to be read. Furthermore, it allowed the providers to generate consultations and 
referral to other providers with the clinical note embedded in the letter. The system also has the capacity to generate letters to patients with normal or abnormal tests results. In addition, the system has many other user-friendly features that enhance the quality of care and help to increase efficiencies. The EMR system was instrumental for documentation of the visits and obtaining meaningful use data for the quality improvement project.

In addition to the EMR, the glucometer reading programs, the insulin pump download program, and the continuous glucose monitor (CGM) reading program was used to download patients' glucometer, insulin pumps, and CGM. These programs helped to analyze the patients' blood glucose reading. Other technology that was also available in the practice was the projector that was used for Microsoft-Power-Point presentations. No added cost for the use of technology was required since the staff already had laptops, computers, and printers. These programs were all used in the current one-on-one usual patient care.

\section{Budget}

To offset the budget, billing for the services continued to generate income for the organization. Billing was accomplished through the regular evaluation and management codes used by the care providers for the medical encounter. The nurse leader and office manager also tracked denials of any claims, the reasons for the denials, and the results of the appeal process.

Implementation cost to the endocrinology office was minimal since this quality improvement project is part of the student's capstone project to fulfill the requirements of the WVSON DNP curriculum. The planning, implementation, and evaluation of the project was done by the student. The planning of the program, implementation and evaluation was already completed as illustrated in this paper. 
The organization was responsible for paying the staff for running the SMA, which included the time needed to set up appointments and running the appointments. It was also responsible for providing light refreshments for the patients to have at break time during the SMAs. In addition, the office provided the conference room, the flyers, as well as any additional printing or copies of reports that were needed for SMAs.

Shared medical appointments, as indicated in the literature, adds quality health-care delivery and also boosts productivity. The estimated return on investment of running an SMA and the cost savings for the quality improvement project is translated not just in improved patient outcomes but in economical savings to the organization. A SMA can triple productivity by doing 4.5 hours of work in 1.5 hours (Brower, 2009). It also increases patient satisfaction as well as provider satisfaction.

The endocrinology office currently schedules a patient every 20 minutes for follow-up appointments. In two time slots of 120 minutes the practice can see a total of 12 patients. The insurance rate reimbursement for a level three appointment is $\$ 121.00$ per patient visit, times 12 patients' times 4 appointment time slots the organization billed for a total of $\$ 5,808.00$. The organization billed SMA participants' insurance for a level five appointment at the rate of $\$ 260.00$. The organization billed for two SMA cohorts of 24 participant's times 4 appointment generates a total of $\$ 24,960.00$. This is a net gain of $\$ 19,152.00$.

The cost to the organization at a scheduling rate of 20 minutes per patient for follow up, for seeing 12 patients required 240 minutes or a total of 4 hours. The FTE cost of the provider, the nurse, and the front office staff for 4 hours is $\$ 292$ ( $\$ 40.00$ for the provider and $\$ 18.00$ for the LPN, $\$ 15$ for front office person). In comparison the SMA cost for the same amount of 12 patients at the same FTE rate is $\$ 146.00$. This SMA represents a cost saving of $\$ 146.00$ per 
SMA. In addition, the SMA provides high quality evidence-based care that that has the potential to generate improved patient outcomes. The budget can be located in Appendix F. Overall, the final cost for the quality improvement project will be minimal.

\section{Congruence of Organization's Strategic Plan to Project}

The endocrinology office of interest is part of a large faith-based organization. The faithbased organization quality-management plan for 2014 with their mission and purpose statement supports the objectives of this quality improvement project. The mission and purpose of the faith-based organization quality process improvement states the following:

\section{Mission Statement}

The faith-based institution "serves as a health ministry, providing compassionate care to people of all faiths in a loving, spiritual environment. God gives us the responsibility to carry out His mission of healing and to promote the well-being of our employees and our community. In doing so, we, the hospital family, fulfill our mission through our:

$\begin{array}{ll}\text { Healing } & \text { Tradition } \\ \text { Understanding } & \text { Ongoing Education } \\ \text { Ministry } & \text { Unity } \\ \text { Advanced Technology } & \text { Care } \\ \text { Nurturance } & \text { Hope }\end{array}$

\section{Purpose of the Organizations Quality Process Improvement Statement}

The Quality Process Improvement focuses on outcomes of care, treatment, and services. Leaders establish planned, systematic, and organization-wide initiatives for process improvement. The leaders set the priorities for process improvement, which are aligned with the 
Hospital's goals for 2014, and ensure leadership and all organizational disciplines providing the scope of care, treatment, and services work collaboratively to develop and execute the improvement activities. The process improvement initiatives are a varied grouping based upon the regulatory requirements, but also based on how each aligns with the goals set forth by leadership. The Quality Management Plan seeks to align this initiative by setting determined goals, structure, and processes to the collections of data generated by the organization" (Wheeling Hospital mission statement 2014).

\section{Evidence of Key Site Support}

First, in the preplanning phase, the approval for the SMA improvement project from the endocrinologist in charge and the clinic director was obtained as evidence of their letter of support included in the Appendix G.

\section{Timeline of Project}

This quality improvement project was proposed as a five phase project. The first phase of the project involved assessment of the problem and preplanning stage of the SMA, included a written submission of proposal to the student's Doctoral Committee and obtaining their approval. The second phase was the submission of the quality improvement project to the WVU IRB. The third phase involved the preplanning stage with the core intervention team. This consisted of collecting all the educational materials, scheduling speakers for the SMA group meetings, posting the flyers, and scheduling patients. The fourth phase was the implementing, running, and evaluating the SMA delivery system. It included collecting base line data and post-SMA data. The fifth phase consisted of analysis of data and dissemination of results at the end of the project. The SMART objectives and timeline for the project are located in Appendix H \& I respectively. 
The nurse leader outlined specific steps for the preplanning stage of the SMA. This included obtaining approval from the endocrinologist and office manger to implement the SMA model. The proposal included a budget and timeline outlining the steps needed to launch the SMA after IRB was secured.

The nurse leader was the key person responsible for implementing the intervention. Her role was vital as change champion and as the knowledgeable practitioner. She recruited other champions among the staff who formed a core intervention team. Their involvement helped to obtain early acceptance to the change project proposed. Open communication among all the stakeholders was imperative for the success of this project. Communication among the team players was face-to-face committee meetings, hospital e-mails, telephone conversations, and committee reports.

\section{Measurable Project Objectives}

The quality improvement project included the following four specific objectives:

1. Patient access in an endocrinology office in northern West Virginia will increase from the current six patients scheduled in a 120-minute time period.

2. Documentation of adherence of the ADA Standards of Care via the diabetic flow sheet will increase compared to pre-SMA.

3. Patient satisfaction with health care delivery will increase post-SMA compared to pre-SMA.

4. Staff satisfaction with health care delivery will increase post-SMA compared to preSMA.

\section{Evaluation Plan}


The participants in the SMA included patients with uncontrolled diabetes who had a preSMA A1C of $8 \%$ or greater and it also included five support staff personnel at the office of interest. Participants with uncontrolled diabetes were identified by initially querying the EMR at the office of interest. Recruitment of patients was initiated after the patients with abnormal A1C were identified. One hundred letters were mailed out to these potential patients but only one patient responded to mailing. Face to face recruitment by the nurse leader and by the other two providers during routine office visits yielded additional participants. There was a total of 36 patients that agreed to participate in the SMA quality improvement project. Only the participants that completed two or more SMA sessions were included in the study. A total of 20 participants completed two or more sessions and 16 completed four or more SMA sessions.

First, the characteristics (gender, ethnic background, age and disabilities) of SMA participants with diabetes were demonstrated by using descriptive statistics. The data were abstracted from the EMR and inputted into a Microsoft Excel spreadsheet and values were calculated using the Excel statistical function tool. The date was tabulated, analyzed and recorded in the Excel spreadsheet. The outcome evaluation was used for capstone project and more important, to help address participants' potential clinical problems.

Second, five support staff volunteered to work the SMA and they alternated working the SMA sessions. Two staff members worked each session. The characteristics (gender, ethnic background, age, and years of working experience) of SMA staff participants were demonstrated using descriptive statistics. The data were verbally reported by the staff. This was inputted into Microsoft Excel spreadsheet and the Excel statistical function key tool was used to compute the values. The data were analyzed and recorded in the capstone paper. 
The data for the four objectives for this quality-improvement project was evaluated by collecting pre-SMA baseline data and compared to post-SMA data. The nurse leader was responsible for data collection, analysis, and dissemination of results at the end of the project. The four objectives above were evaluated as follows:

Objective 1: Increased Access to Care. The original proposal, was to evaluate increased access to care by using descriptive statistics. Before the SMA intervention, patients were scheduled at a rate of six patients per two-hour period (120 minutes). Each of the two 12-patient SMA cohorts met four times for 120 minutes per visit. The average number of patients seen in these eight 120 minute SMA visits were compared to the average of six patients that are scheduled per 120 minutes currently (pre-intervention).

Evaluation for objective 1 was initially evaluated by using descriptive statistics but after consultation with the new West Virginia School of Nursing statistician, the actual pre-SMA appointments were compared to post-SMA sessions. The pre-SMA schedule of clinical nurse leader that ran the SMA was used for comparison. In addition, the pre-SMA appointments chosen for comparison were appointments that took place the previous week of the SMA. The same days that the SMA were conducted and the same time frame was used for comparison. Furthermore, the rate of no show was calculated for both the pre-SMA and the SMA sessions. Thus, the days and time frame used for pre-SMA comparison for Cohort 1 was the first Friday of the month from 10:30 to 12:30 and for Cohort 2, it was compared to the third Wednesday of the week from 1330 to 1530 . SMA cohort one were scheduled the second Fridays of month from 10:30 to12:30 and SMA cohort number two were scheduled on the last Wednesday of the month from 1330 to 1530. 
The nurse leader's daily schedule was generated from the EMR for the given dates shown above. The pre-SMA and post-SMA dates, number of patients scheduled, number of patients seen and the no show rate was recorded in a Microsoft Excel spreadsheet and a descriptive analysis was run using the Microsoft Excel statistical function key tool. A total of 22 appointment days were compared 11 pre-SMA to 11 post-SMA. The data were tabulated, analyzed and recorded in the Excel spreadsheet. The outcome evaluation was used for this capstone project and it was also used as evidence to show positive findings for continuing the SMA sessions to administration.

Objective 2: Adherence to ADA Standards of Care. Objective 2 was evaluated by using Chi square. The proportion of post-intervention charts on which all ADA standards of care were met was compared to the pre-intervention proportion charts on which all ADA standards were documented. Adherence to the ADA standards of care was measured via the diabetic flow sheet (Appendix E). Charts on which all 17 items of the diabetic flow sheet were recorded were considered having met the ADA standards of care. If one or more items were not recorded, the ADA standards of care were not met.

Evaluation for objective 2 was appraised by using Chi square comparison for proportion of pre-SMA documentation of the ADA standards of care to the proportion of post-SMA documentation of SMA ADA standards of care. The chair of the capstone gave permission to the West Virginia School of Nursing statistician to assign an epidemiology PhD student to run the statistical analysis for objectives 2, 3, and 4. This was done to decrease added expense of purchasing a statistical software program for the DNP student. The DNP student worked closely with epidemiology student. 
The DNP student analyzed and recorded the EMR's ADA standards of care flow sheet for the 20 participants that completed 2 more sessions. The values were extracted and recorded in a Microsoft Excel spreadsheet and that was sent to the epidemiology student to compute. STATA software was used to compute the Chi square statistical analysis. The nurse leader tabulated, analyzed, and recorded the findings. The outcome evaluation was used for the capstone project and it was also used as evidence to show administration how the diabetic flow sheet generates meaningful use data. Meaningful use data, if used correctly can help increase quality of care for patients with diabetes and it can demonstrate excellence in the medical care given. In addition, meaningful use can be used to generate increased revenue. The individual outcomes of the diabetic flow sheet with ADA standards of care identifies participants' risk factors. This tool, when used appropriately, can help individualize the participants' care to prevent diabetic complications.

Objective 3: Patient Satisfaction. Objective 3 was evaluated using a paired t-test. Patient satisfaction was measured using an adaptation of Hiidenhovi, Laippala, and Nojonen's (2001) patient-oriented instrument to measure service quality in outpatient departments. This instrument has reported content and constructs validity (Hiidenhovi, Laippala, \& Nojonen's, 2001). The tool can be found in Appendix J. It was developed in Finland and includes 12 items on a Likert-like scale of one to seven. The author of the instrument gave written permission to use the instrument (see Appendix K). The instrument was administered pre-and post-intervention and raw scores (sums) were used for the one-sided paired t-test to test the increase of patient satisfaction. To decrease chances of bias and to maintain patients' confidentiality, the patients were assigned a numerical number that was blind to the nurse leader. The procedure to assure patients' confidentiality were the following six steps. 1) The assessment tools were distributed to 
the participants randomly in large $10 \times 13$ inch sealed envelopes. 2) The package contained two smaller envelopes labeled pre- and post-instrument. The assessment tools had a matching numerical number to assure appropriate matching of assessment tools for evaluation at the end of the program. 3) The completed pre-test was placed back in the large envelope. 4) The patients were instructed to leave the post-test in the package (to be completed at the end of the improvement project); they were also instructed to seal the envelope, and to write their name outside the envelope. 5) At the end of the program the patients were handed their envelopes and instructed to complete the post test. 6) A second large $10 \times 13$ inch envelope was distributed and the patients were instructed to place their post-test assessment in this new envelope along with the pre-test that was completed in the beginning of the program. These envelopes were sealed and returned to the nurse leader.

The patient satisfaction with health care delivery data were initially tabulated in a Microsoft Excel spreadsheet. As above, the chair of the capstone gave permission to the West Virginia School of Nursing statistician to assign an epidemiology PhD student to run the statistical analysis for objective three. First, The DNP student tabulated the difference of preSMA patient satisfaction with health care delivery to the post-SMA patient satisfaction with health care delivery. The epidemiology $\mathrm{PhD}$ student used STATA software to run a paired t-test and since the data were so small he also ran a non parametric t-test. This was added to see if there was a significant difference. The nurse leader and $\mathrm{PhD}$ student worked closely together. First, the nurse leader provided the PhD student the Microsoft Excel spreadsheet with the raw data from the pre-and post-intervention satisfaction questionnaire. The nurse leader and the epidemiology student communicated via e-mail and by phone to discuss the process and to share the data. The epidemiology $\mathrm{PhD}$ student provided the nurse leader with the raw data and all 
answered all questions regarding the data as needed. The nurse leader tabulated, analyzed and recorded the results in the Excel spreadsheet. The outcome evaluation was used for the capstone project and it was also used as evidence to show administration positive findings for both the one-on-one to-patient-to-provider visits and for continuing the SMA sessions.

Objective 4: Staff Satisfaction. Objective 4 was evaluated by using paired t-test. Staff satisfaction was measured using an adaptation of Hiidenhovi, Laippala, and Nojonen's (above). As above the author of the instrument gave written permission to use an adaptation of the instrument. The staff satisfaction tool is in Appendix L. The patient satisfaction survey was adapted for staff by using seven of twelve original items. The instrument was administered preand post-intervention and raw scores (sums) were used for the one-sided paired t-test to test increase of staff satisfaction. The same procedure and process as above in objective three was repeated with the staff to assure staff's confidentiality and to decrease chances of bias.

The outcome evaluation for the staff satisfaction was used for this capstone project and it was also used to empower the support staff at the practice of interest. The staff's results can also be used by administration to promote the practice. Administration can also use these results for possible future SMA implementation in other settings.

\section{Results}

The results of the quality improvement study were very positive. First, the demographic information of the participants is presented followed by the four objectives. The results also include the following: (1) extent of how the objectives were met, (2) the key facilitator that made the objective achievable, (3) key barriers to meeting any of the objectives, and (4) positive and negative consequences of SMA quality improvement project. 
A total of 20 participants completed two or more SMA sessions. The demographic characteristics of participants included a total of fourteen females and six males. The percentage breakdown was $70 \%$ females and $30 \%$ males. The ethnic background included two African Americans, one male and one female. There was a total of eighteen Caucasians, 13 females and five males. Ninety percent of the participants were Caucasian and 10 percent were African American, 65\% were female Caucasians and 25\% were male Caucasians. Ten percent were African Americans with five percent male and five percent female participants. The African American female is legally blind due to retinopathy.

The ages of the participants ranged from 53 years old to 73 years old. The mean age was 62.35 years old. The male ages ranged from 55 years of age to 72 years of age with a mean average of 63.50 years of age. The female ages ranged from 52 years of age to 73 years of with a mean average of 63.12 years of age.

Demographic information regarding the support staff is the following: all the staff were females, one African American and four Caucasian. Their ages ranged from 29 to 50 years with the mean age of 42.2 years of age. They have a combined total of 71 years of experience, eight years of minimum experience and 21 years of maximum experience, and a mean average of 14.2 years of experience.

Objective 1. Patient access in an endocrinology office in northern West Virginia was increased from the current six patients scheduled in a 120-minute time period. A total of 66 patient appointments were schedule for the 11 pre-SMA sessions but only 53 patient appointments were seen, this is an average of 4.8 patients seen in 120 minutes. Thirteen patients were no show and this translates to an average no show rate of 1.18 -no shows per 120 -minutes time frame. A total of 122 patient appointments were schedule for the 11 SMAs but only 104 patient 
appointments were seen, this is an average of 9.4 participants seen per 120-minute SMA. Eighteen participants were no show and this translates to a no show rate of 1.6 no shows per SMA 120-minute time frame.

The total difference of 11 pre-SMA visits to 11 post-SMA visits scheduled was 56 more patient appointments scheduled for the SMA time frame. The total difference for 11 pre-SMA to 11 post-SMA actual participants seen was 38 . This is 38 more participants were seen in the SMA format time frame of 120-minutes. The average scheduled participants difference pre-SMA to post-SMA was 5.09 more patients were scheduled for the SMA format time frame. The difference of actual average number of participants seen pre-SMA to post-SMA was 3.45 more patients were seen per 120-minutes time frame. The no show rate difference pre-SMA to postSMA was 0.45 .

The key facilitator for achieving the increased number of patients in the SMA format is due to the extra time that is available during the appointment. This extra time allowed the provider to keep the participants engaged and created an environment of patient acceptance and open communication between the participants and SMA staff. In addition, the principle catalyst for the success of the SMA is due to the organization's willingness to allow the nurse leader to implement this quality improvement project. Barriers to increasing number of participants may be due to patients' lack of knowledge regarding the benefits of the SMA format. Many participants when initially when approached stated they had already attended a diabetes educational program. The SMA is not just an educational program because it includes all the elements of a one-on-one patient-to-provider visit. The time needed to participate in the SMA may be an additional barrier patients may not have the extra 90 minutes needed to participate in 
SMA. Since the SMA was offered during the 8:00am to 5:00 pm working day this may have excluded the participants that have full-time jobs and are not able to take time off from work.

The increased revenue generated for the SMA time slots was a very positive unintended consequence of the SMA format. In the one-on-one patient-to-provider 20-minute appointment, the organization billed $\$ 120.00$ for a level three visit. In the SMA 90 -minute per patient format the organization billed for a level five visit at a rate of $\$ 260.00$. The 11 pre-SMA included a total of 53 actual patient visits at a rate of $\$ 120.00$ per visit. It generated a total of $\$ 6,360.00$. In the 11 post-SMA visits a total 104 actual patient visits were completed. The 90 -minute visit per participant was billed at a level 5 appointment at the rate of $\$ 260.00$ and generated a total of $\$ 27,040.00$. The net gain for the organization in the 11 post-SMA was a total of $\$ 20,680$.

In conclusion, patient access to care using the SMA health care delivery increased both in the number of patient appointments scheduled and the actual number of patients seen. Fifty-six more patient appointments were scheduled in the 11 SMA format of 120-minute time frame. The actual number of patients seen also increased by 38 more patients than usual one-on-one patient-to-provider appointment time frame. The no show rate difference was slightly higher for the SMA group but this is due to the increased number of patients schedule for the SMA. The SMA appointments also generated increased revenue.

Objective 2. Documentation of adherence of the ADA Standards of Care via the ADA diabetic flow sheet did not increase compared to pre-SMA and therefore was not statistically significant. The proportion of pre-SMA to post-SMA standards of care documented showed no change, they were found to be equal. Although objective two was not obtained, the results are very positive for the organization because it shows that the practice of interest was compliant with the ADA standards of care documentation prior to implementation of the SMA quality 
improvement project. In addition, is important to point out that since the inception of the SMA quality improvement project the 2016 ADA Standards of Care were released and the Standards are very similar to the 2014 Standards. Since both Standards are similar the current ADA diabetic flow sheet remains relevant.

The key facilitator for achieving 100\% ADA Standard of Care documentation was due to the use of EMR ADA flow sheet. The ADA flow sheet was developed by the nurse leader a year earlier in preparation for NCQA accreditation. A positive unintended consequence for documentation of the ADA standards of care resulted in the ability to report patients' biophysical markers that are translated into meaningful use data. The meaningful data, if used appropriately will improve patient outcomes. Although the biophysical markers were not part of the capstone objectives they are imperative to help improve participants' outcomes.

The pre-and post-SMA biophysical markers tracked via the ADA diabetic flow sheet are illustrated on Table 1. The table also shows the mean average, the minimum and maximum of each variable. In addition, the total percentage change for all the biophysical markers were calculated and illustrated in the Table 1. There were seven out of ten positive changes in biophysical outcomes. Table 2 indicates the number of participants that had an eye exam, retinopathy, foot exam, pneumonia vaccination, and influenza vaccination. Table 3 indicates the type of diabetes treatment plan the participants are receiving. In addition, the table also documents the number of participants using either a V-go insulin patch delivery device or an insulin pump.

Table 1

Total Percentage Pre-and Post SMA Biophysical markers

\begin{tabular}{lcccc}
\hline Variables & Mean & Min & Max & Difference \\
Biophysical outcomes & & & \\
\hline
\end{tabular}

$\mathrm{A} 1 \mathrm{C}(\%)$ 
Running Head: ENDOCRINOLOGY SHARED MEDICAL APPOINTMENTS

$\begin{array}{ll}\text { Pre-SMA } & 9.655 \\ \text { Post-SMA } & 7.68 \\ \text { \%Change df } & -6\end{array}$

Systolic Blood Pressure (mg/dl)

$\begin{array}{ll}\text { Pre-SMA } & 129 \\ \text { Post-SMA } & 123\end{array}$

$\%$ Change df

Diastolic Blood Pressure

\section{Pre-SMA}

Post-SMA

$\%$ Change df

BMI $(\mathrm{kg} / \mathrm{mg} 2)$

Pre-SMA

Post-SMA

$\%$ Change df

Total Cholesterol (mg/dl)

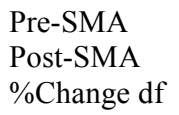

Pre-SMA

Post-SMA

$\%$ Change df

HDL (mg/dl)

Pre-SMA

Post-SMA

$\%$ Change df

Triglycerides (mg/dl)

Pre-SMA

Post-SMA

$\%$ Change df

LDL (mg/dl)

$$
\begin{aligned}
& \text { Pre-SMA } \\
& \text { Post-SMA } \\
& \text { \%Change df }
\end{aligned}
$$

Creatinine (mg/mmol)

Pre-SMA

Post-SMA

$\%$ Change df

eGFR

Pre-SMA

Post-SMA

$\%$ Change df

Urine micro albumin creat/ ratio
129

$-6$

75.6

76.1

.50

35.37

35.41

0.04

173

171.4

$-1.6$

46

52.6

5.7

170.1

140.85

$-29.25$

93.1

90.85

$-22$

0.878

0.954

0.076

58.1

57.25

$-1$

163.75
198.26
44.345
8.1

6.6

$-48$

110

102

$-48$

150

152

22

13.4
10.0

22

90

100

16

49.3

47.7

4.70

25.1

$-4$

105

96

$-104$

296

300

116

88

159

129

27

$-20$

352.0

272.0

54.0

$-140$

34

36

$-82$

191.0

213.0

114.0

0.47

0.60

$-0.28$

1.6

1.5

0.56

43.0

35

$-20$

60

69

11
1.975

6

$-0.5$

$-0.04$

1.6

$-6.6$

29.15

2.25

$-0.076$

0.85

1114.4

1795.2

680.80

$-34.51$
0.47
0.93

$-49.01$

Table 2

Eye exam and Vaccine documented

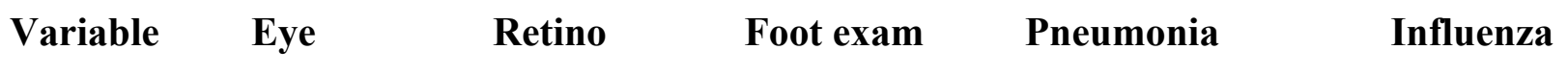




\begin{tabular}{lllccc} 
& Exam & pathy & exam & vaccine & vaccine \\
\hline Yes & 13 & 6 & 20 & 8 & 10 \\
No & 7 & 14 & 20 & 12 & 10 \\
$\%$ & $65 \%$ & $30 \%$ & $100 \%$ & $40 \%$ & $50 \%$ \\
\hline
\end{tabular}

Table 3

Treatment plan

\begin{tabular}{llllll}
\hline Variables & Oral & Insulin & $\begin{array}{c}\text { Combination } \\
\text { Oral/insulin }\end{array}$ & V-go device & Insulin Pump \\
\hline Yes & 4 & 6 & 10 & 3 & 4 \\
No & 16 & 14 & 10 & 17 & 16 \\
\hline
\end{tabular}

Objective 3. Patient satisfaction with health care delivery increased post-SMA compared to pre-SMA. Only the data from the 16 patients that completed a total of four or more SMA were tabulated. There was a total of 12 (observations) questions that were included. The average pre-SMA patient satisfaction with health care delivery was 6.505 . The average post-SMA patient satisfaction with health care delivery was 6.776. The difference of pre-SMA patient satisfaction with health care delivery to post-SMA patient satisfaction with health care delivery was -0.272 . The results of the one-sided paired t-test for pre-SMA to post-SMA patient satisfaction was $t=$ $-3.105, \mathrm{p}$-value $=0.01$. Due to the small samples size, a Wilcoxon signed-rank test was conducted, and the results was $\mathrm{z}=-2.510$, $\mathrm{p}$-value $=0.006$. Both results indicate statistically significant positive differences between patient satisfactions from pre-SMA to post-SMA.

The key facilitator for the significant patient satisfaction with the SMA format is the same as it was for objective 1. As stated above under objective 1, the key facilitator for this positive outcome is due to the extra time that is available during the appointment. This extra time allowed the provider to keep the participants engaged and created an environment of patient 
acceptance and open communication between the participants and SMA staff. In addition, participants' comments in their evaluation were all very positive (see Appendix M).

A positive unintended consequence for this objective was the fact that the participants were very satisfied with the quality of care they received pre-SMA intervention. It is believed that due to this patient satisfaction the participants trusted the nurse leader and volunteered to participate in the SMA. Other positive unintended consequences were the comments regarding the pre-SMA and the SMA. The negative comments regarding the phone system in the office of interest is a system-wide problem and administration is aware. These comments were shared with the office manager and although they were planning on replacing the current phone system now they are moving to replacing the phone system sooner. It is hoped that the new system will not drop calls and patients will be able to have an improved experience. Many of the other suggestions to improve the SMA were also implemented to the current SMAs, for example the one-on-one patient-to-provider time is now completed in an adjacent room, vitals and review of systems are completed prior or after to the speaker's presentation. Participants are being reminded to try to hold private conversation to a minimum during the speaker's presentation.

Objective 4. Staff satisfaction with health care delivery increased post-SMA compared to pre-SMA. Only the data from the five staff that worked in the SMA was tabulated. There was a total of seven (observations) questions that were included. The average pre-SMA staff satisfaction with health care delivery was 4.762 . The average post-SMA staff satisfaction with health care delivery was 5.381 The difference of pre-SMA staff satisfaction with health care delivery to post-SMA staff satisfaction with health care delivery was -0.619 . A one-sided paired t- test and Wilcoxon signed-rank test were computed in STATA. The results of the one-sided 
paired t-test for pre-SMA to post-SMA staff satisfaction was $\mathrm{t}=-10.3313$, $\mathrm{p}$-value $=0.0000$. Due to the small samples size, a Wilcoxon signed-rank test was conducted, and the results was $\mathrm{z}=-2.410, \mathrm{p}$-value $=0.008$. Both results indicate statistically significant positive differences between staff satisfactions from pre-SMA to post-SMA.

There were multiple key facilitators for this objective to reach a significant staff satisfaction outcome with the SMA format. First, the positive staff satisfaction is due to the extra time the support staff had during the SMA format to interact with patients. Second, this extra time allowed them to engage the participants and individualize their care. Third, it also allowed them to answer all the participants' questions without being hurried. Fourth, the extra time with same patients also allowed the staff to build stronger patient-to-provider relationships. In addition, the staff verbalized that they also learned new information from the presenters. They stated the new knowledge "filled many holes" that would help them improve the care they deliver.

The level of years of experience the staff has was an unintended consequence which may contributed to their willingness to work the SMA. In addition, their positive attitude and comfort level added value to the SMA sessions. This staff is a seasoned group of professionals that are comfortable with their jobs and are not afraid to try new health care delivery methods to improve patient outcomes. In conclusion the satisfied staff helped to generate good patient outcomes.

\section{Discussion and Recommendations}

This section includes a discussion on how the chronic care model supported the SMA. It also outlines specific recommendation for the office of interest to assure continual use of the SMA quality improvement project. In addition, it will outline global recommendations needed to 
help improve outcomes for patients with diabetes. Furthermore, recommendations are outlined for expansion of the SMA format in other settings. Finally, this section will end with a discussion of the capstone process and its positive and negative unintended outcomes.

\section{Evidence how the Theoretical CCM Model Supported the SMA}

The Chronic Care Model supported and guided the implementation of the SMA health care delivery system in the office of interest. This model worked well because the model is a proactive evidence-based-model designed to help practitioners change from the current outdated acute care model to one that is proactive and intended for patients with chronic illnesses like diabetes (Wagner et al., 2001; GHRI, 2014). The model's six evidence-based elements (organizational support, delivery system design, community resources, self-management, clinical information systems, and decision support) supported the SMA as a framework to develop, implement and evaluate the SMA quality improvement project.

Organizational support is the initial element of CCM. In the office of interest organizational support was imperative for the success of the SMA. The organization's mission statement mirrors the goals of this element which fosters open communication and promotes safe and high quality care (Wagner et al., 2001; GHRI, 2014). The nurse leader achieved this element of the model by first obtaining buy in from the endocrinologist that is responsible for the practice and then by obtaining written permission from administration to complete the quality improvement project. Administration provided the financial support needed to complete the SMA appointments. It also directed the information system (IT) to help the nurse leader as needed with the EMR.

The second element of the CCM is the delivery system which also provided a key foundation for the success of the SMA quality improvement project. First, the delivery system 
portion of this element calls for assuring effective, efficient clinical care and self-management support (Wagner et al., 2001; GHRI, 2014). The primary goal for implementing the SMA was to assure effective, efficient clinical care with a self-management support. Second, the element calls that health-care provider' roles, responsibilities, and job descriptions are well defined (Wagner et al., 2001; GHRI, 2014). In the pre-planning phase of the project the nurse leader outlined the roles of the health care team. The job description and role responsibilities were essential to give the providers a realistic working framework to run the SMA. Third, the SMA is an evidence based health care delivery system with planned interventions to meet the needs of patients with chronic illness like diabetes. Evidence-based health care delivery system with planned intervention to support the chronic illness is another key element of the theoretical mode (Wagner et al., 2001; GHRI, 2014). Finally, the SMA also delivered culturally appropriated care and follow up care for all the participants. Culturally appropriate care and follow up care is an intricate part of this element (Wagner et al., 2001; GHRI, 2014).

Community resources and policies is the next element of the CCM which also supported the SMA quality improvement project. The element calls for developing and establishing a relationship with community-based resources in order to meet the health-care management needs of patients and to avoid duplication of services (Wagner et al., 2001; GHRI, 2014). The nurse leader affiliated with other community medical leaders to provide educational lectures during the SMA. In addition, these leaders serve as a referral source. The model provides a framework to develop and implement policies to improve patient care (Wagner et al., 2001; GHRI, 2014). One of goal of SMA was to provide a framework that allowed increased access for participants with diabetes to quality medical care. It also provided mechanisms to empower the patient and provider to improve patient outcomes. 
The self-management element is the fourth element of the model. It requires empowering patients by giving them the tools needed to take control of their own disease process (Wagner et al., 2001). The SMA format strives to empower the participants via education and tools to allow them to manage their diabetes. The second half of the SMA was devoted to teach the participants self-management strategies. The strategies included shared decision making in which the provider guided the participant to make changes by allowing the participant to set his or her own goals. The participants were encouraged to make appropriate changes one step at a time. Positive health behaviors were reinforced with the teaching techniques used during the SMA.

Decision support is the fifth element of the model. The nurse leader followed and implemented all the requirements of this element. This element promotes medical care that is consistent with evidence-based medicine (Wagner et al., 2001; GHRI, 2014). The current SMA is an evidence-based health care delivery system that provided medical care that was grounded in the ADA clinical guidelines. The SMA health care delivery system takes into account the patients preferences. The element calls for the evidenced-based guidelines to be embedded in disease-based registries (Wagner et al., 2001; GHRI, 2014). The ADA diabetic flow sheet is embedded in the office of interest's electronic medical records. It has reminders to promote compliance with the ADA guidelines. The ADA flow sheet generates meaningful use outcome data. The clinical guidelines and medical information was taught to the participants to empower the participants by encouraging their involvement in their care. In addition, the nurse leader, SMA staff and guest speakers used proven teaching methods to educate the participants. The nurse leader involved experts to address diabetic complications. The nurse leader maintains her credentials by participating in ongoing continuing education to assure up-to-date clinical 
knowledge. The EMR also utilizes guidelines that are integrated in the system with timely reminders, feedback, and standing orders that enhance the clinical decision process.

The last objective of the CCM is the clinical information system element. This element strives to enhance quality care by having access to key data for the individual patient and for a population of patients (Wagner et al., 2001; GHRI, 2014). The EMR system used during the SMA at the practice of interest enhanced the quality of care. This was accomplished by the system giving timely reminders, by allowing individualized planned care, and by the sharing of information with patients and providers, which allows the practice to monitor its performance.

In conclusion, the theoretical framework of the CCM provided significant strategic support in the planning, the implementation, and the evaluation of the SMA quality improvement project. Evidence that the CCM model's framework supported the SMA health care delivery system in the practice of interest was illustrated in the positive outcomes results of the project as described in the results section of this paper.

\section{Recommendations to Assure Continual Success of the SMA}

The results of the SMA quality improvement project were positive as indicated above. The faith-based organization's quality improvement plan process calls for the quality improvement to focus on outcomes of care, treatment, and services. It also calls that leaders establish planned, systematic, and organization-wide initiatives for process improvement (Wheeling Hospital mission statement 2014). The following recommendations to continue and to improve the SMA care delivery mirrors the organizations quality improvement process. These recommendations are based on the current outcomes, treatment plan and services that the SMA capstone project provided. 
First, the SMA health care delivery system should continue at the office of interest. It should include both controlled and uncontrolled patients with diabetes. It should include the current patients with diabetes from the endocrinology office and newly diagnosed patients from primary care settings. In order to recruit newly diagnosed patients, the endocrinology office should form a partnership with Family Health and other primary care providers in the system and outside the system and open the SMA to their newly diagnosed patients. Early intervention with this patient population is key in preventing the devastating complication of the disease process. There is new research evidence on "metabolic memory" which indicates that early tight glycemic control is vital to decrease diabetic complications. Metabolic memory is currently recognized as a result of prolonged damage produced by hyperglycemia early in the disease process. The adverse effects appear irreversible even when elevated glucose is corrected later in the disease process (Aschner, \& Ruiz, 2012).

As a result of this new evidence regarding metabolic memory and the evidence that the SMA health care delivery process produces positive outcomes, the SMA format should be offered to all new diabetic patients. The patients should all be initially evaluated as new patients for the endocrinology office of interest. The participants should be encouraged to complete a total of four SMA sessions. At least one SMA session should be offered in the early evening or on Saturday in order to give access to patients that work. The number of participants per SMA should not exceed 12 patients. Greater than 12 participants per SMA increases the time frame of the SMA. The participants from the primary care facilities that complete the program should be sent back to their primary care settings. If the patients from the primary care offices wish to remain with the endocrinology office they should be allowed to stay with the endocrinology office. 
A separate SMA targeted for only young participants between ages 18 to 26 should be tested and implemented. Young adults with diabetes encounter numerous barriers that make adherence to good glycemic control difficult (Borus \& Laffel,2010). Tested evidence-based strategies that appear to work with this age group include motivational interviewing and teaching problem-solving techniques, and allowing flexible dietary behaviors (Borus \& Laffel,2010). The SMA uses both motivational interviewing and teaches participants problem-solving techniques. In addition, the added advantage of meeting with other patients of the same age group adds peer group support that may enhance the experience. Borus and Laffel (2010) also found that using technology for follow up and to engage this age group is an added benefit. Technology tools should be considered to be added for this age group as well.

\section{Recommendations for Other Setting to Implement SMA}

The death rate for white middle aged ( 45 years old to 54 years old) citizens in the state of West Virginia has increased by as much as 70\% since 1980 (Case, \& Deaton, 2015). Forty percent of the death rate increase is due to suicide and drug abuse, but the other $60 \%$ is due to other causes such as heart disease, diabetes, respiratory disease and other chronic health problems (Case, \& Deaton, 2015). The health disparities for this age group may be routed in many socioeconomic factors that directly contribute to the higher death rate. The disparities are beyond the focus area of this discussion but the need for early quality health care for the white middle age population in Appalachia is vital. The SMA format works well with other chronic health illness such as coronary heart disease, atrial fibrillation, congestive heart failure, and chronic obstructive lung disease (Noffsinger \& Sawyer, 2003). The current health care system needs to take urgency to this mortality rate increase. The organization of interest offers advanced care in cardiology and pulmonology. The SMA health care delivery system, if implemented 
correctly, offers an alternative that will not increase cost to the organization but will increase access to care and improve outcomes.

\section{SMA Process and Unintended Outcomes}

The process for implementing the SMA quality improvement project was achieved by using all the elements of the chronic care model. The fact that the clinical support staff were a mature, experienced group of providers gave extra quality to the care that was given during the SMA. The staff's level of experience and their willingness to try a new health care delivery system made the transition from the usual care to the SMA health care delivery much easier to implement. Administration's commitment to improving quality of care is also a contributing factor that was key for the implementation of the SMA.

Unintended consequences regarding SMA implementation includes the following: First, it was unexpected to find that only $65 \%$ of participants had a comprehensive eye exam and that $30 \%$ were found to have retinopathy and one participant was legally blind due to diabetes. Participants reported they did not have an eye exam due to lack of insurance coverage and because some did not believe diabetes causes a problem to their sight. Providers need to find strategies to increase comprehensive eye examination. Strategies include to continue to provide education, increase awareness through traditional media outlets and include social media awareness of the problem in addition to forming partnerships with local ophthalmologists to provide services at a discounted price.

Second, only $40 \%$ of the participants received a pneumonia vaccine and only $50 \%$ received an influenza vaccination. Strategies should also be implemented to increase the vaccination rates. Once again education needs to continue and awareness needs to be promoted via traditional and social media. The organization should also partner with the local health 
department to promote and distribute vaccinations. Another strategy that may increase vaccination is to include vaccination during the SMA.

Third, it was surprising to see that participants that completed all four SMA sessions requested to continue to attend additional SMA meetings. This may be due to the added support and internal group dynamics that the groups meetings provided. It was also interesting that some of the participants expressed the need for increased privacy although they were told and agreed in their consent that the shared medical appointment was going to be in a group setting.

In conclusion, this discussion and recommendation section explained how the chronic care model was used as road map to implement the capstone. Recommendations were outlined to continue and expand the SMA health care delivery system at the endocrinology office of interest. It also outlined other areas that the SMA format may be use to meet the needs of patients with other chronic health problems. Finally, it discussed the process and of unintended consequences.

\section{Attainment of DNP Essentials}

The last section of this report includes how this capstone project achieved the eight Doctor of Nursing Practice (DNP) essentials. The essentials were outlined in the 2006 American Association of Nursing (AACN) position statement. These essential are the following: (1) scientific underpinnings for practice, (2) organizational and systems leadership for quality improvement and systems thinking, (3) clinical scholarship and analytical methods for evidencebased practice, (4) information systems/technology and patient care technology for the improvement and transformation of health care, (5) health care policy for advocacy in health care, (6) interprofessional collaboration for improving patient and population health outcomes 
(7) clinical prevention and population health for improving the nation's health, and (8) advanced nursing practice. The DNP degree is focused on preparing the individual nurse at the highest level of education. It concentrates on practice that is innovative and evidence-based, reflecting the application of sound research findings (American Association of Colleges of Nursing [AACN], 2006). The above was achieved in part because the core background in the nurse leader's professional training, certification and licensure are rooted in the above essentials. Evidence for this strong foundation is found in her masters in nursing administration degree, in her post-graduate masters certificate in family nurse practice education, in her DNP course study, in her current nurse practice certification from the American Nurses Credentialing Center (ANCC), and in her family nurse practitioner licensure from West Virginia Board of Nursing. The nurse leader's background facilitated the SMA quality improvement project to also meet the requirements.

\section{Scientific Underpinnings for Practice}

The first element of the DNP essentials calls for three features to be addressed. First, "Integrate nursing science with knowledge from ethics, the biophysical, psychosocial, analytical, and organizational sciences as the basis for the highest level of nursing practice" (AACN, 2006). Second, it requires the use of "science-based theories and concepts" (AACN, 2006). Third, it also requires to "develop and evaluate new practice approaches based on nursing theories and theories from other disciplines" (AACN, 2006).

The SMA quality improvement project achieved all the three features of this element in the in the following way. First, ethic principles were assured for the SMA project by first obtaining IRB by West Virginia University IRB committee. Second, by the patients signing the consent to participate in the quality improvement project. Third, by the staff and the participants 
honoring the HIPPA regulations. Fourth, by the nurse leader and the staff following the standards of care as set by the faith-based organization. And finally by the nurse leader following the nursing professional code of ethics.

The biophysical, psychosocial, analytical and organizational science was achieved by following the American Association of Clinical Endocrinologist and the American College of Endocrinology (AACE/ACE) clinical guidelines for the treatment of diabetes which are rooted in evidence-based science. The second and third feature of this essential element was achieved by using the chronic care model as a road map to plan, implement and evaluate the SMA quality improvement project.

\section{Organizational and Systems Leadership for Quality Improvement and Systems Thinking}

The second DNP essential element was achieved in the following way. First the SMA quality improvement project was designed to increase access to patients with diabetes in northern West Virginia. Increased access to advance care is needed to help decrease the health disparities in the Appalachian region as illustrated in the first portion of this paper. The project's success is also an important strategy to help decrease mortality for the middle aged white population with chronic illnesses in the state. The nurse leader worked closely with administration from the faithbased organization of interest and with the endocrinologist at the office of interest to assure all the hospital polices and directives were followed. The participants, including both the patients and staff all volunteered to participate in the project. A budget was developed and accepted by administration to cover the cost of the SMA quality improvement project. The evaluation process demonstrated that the project is feasible and it can achieve both increased safe quality of care with positive outcomes and increased revenue to the organization. Advanced communication tools such as EMR generated letters, system phone call reminders for 
appointments, and EMR letters generated with lab results were some of the tools use to assure patient safety and confidentiality.

The SMA health care delivery format sees patients in a group setting. This was explained to all the patients prior to their participation. In order to protect their privacy initially the one-onone patient-to-provider portion of the meeting was completed behind a privacy screen. But later via the evaluation process some participants expressed that more privacy would be beneficial. After, this the one-on-one patient-to provider portion was moved to a separate adjacent room.

\section{Clinical Scholarship and Analytical Methods for Evidence-Based Practice}

The third element of the DNP essential has seven separate key principles that were achieved in the following manner. First, the capstone project was not designed to generate new knowledge it was designed to integrate existing knowledge by applying evidence-based knowledge into practice. This was accomplished by first completing a systematic literature review of SMA health care delivery process as illustrated in this paper. Second, the capstone project illustrated eight specific problems in regards to why diabetes in West Virginia and in the northern West Virginia region continues to be a multidimensional problem. Diabetes prevalence was illustrated using national, state and regional statistics. The project also analyzed barriers to care. Third, as illustrated in this paper the capstone project was designed as a patient-centered quality improvement project that is safe, timely, effective, efficient, equitable and cost effective. Fourth, the capstone used current evidence-based practice guidelines to achieve positive patient outcomes. Fifth, information technology and research methods were optimized to carry out this quality improvement project. The use of information technology was illustrated with the use of the Sunrise EMR system and the EMR's diabetic flow sheet. The use of research methods was 
illustrated in the literature review and in the capstone design and the evaluation process for the capstone. Sixth and seventh, it is hoped that as a result of this capstone, the findings will be published and help others generate similar quality improvement projects.

\section{Information Systems/Technology and Patient Care Technology for the Improvement and Transformation of Health Care}

As illustrated in element three the use of the hospital's EMR system fulfills this element as well. It should be noted that the diabetic EMR flow sheet was developed by the nurse leader in conjunction with the information system department. This flow sheet allows the system to generate meaningful use data. It also allows the provider to assure that the ADA standards of care are being applied to the care of the patient. The flow sheet also gives the provider reminders when the patient does not meet the standards of care. For example, if the patient's low lipid protein is high a window opens up reminding the practitioner that a lipid protein lowering medication should be considered.

\section{Health Care Policy for Advocacy in Health Care}

The capstone met the fifth element of the DNP essential by advocating for increase access to care for a diabetic population of patients in northern West Virginia. The capstone quality improvement project also will influence a change in the rate patients are schedule when the SMA format is used by increasing the number compared to the one-on-one patient-toprovider format. It will also change the policy in privacy for the patients that participate in the SMA health care delivery system. Because the format is a group process patient privacy will not be able to be guaranteed.

\section{Interprofessional Collaboration for Improving Patient and Population Health Outcomes}


The sixth element of the DNP essentials as stated above was achieved by forming a partnership with other clinical leaders to provide educational presentations. The nurse leader was responsible for communicating and scheduling the speakers. The experts also served as a referral source for patients who developed complications such as coronary heart disease, eye problems, neuropathy, or nephrology problems.

\section{Clinical Prevention and Population Health for Improving the Nation's Health}

The seventh element of the DNP essential was met in this capstone in the following way. First, the prevalence of diabetes in the nation, in West Virginia and in northern West Virginia was analyzed. This data helped to illustrate the degree of the diabetic problem. Second, aggregated data that showed the degree of multi-organ damage that occurs due to complication of diabetes was also presented in the first part of this paper. Third, the financial impact of diabetes is also illustrated. This illustrated how diabetes increases medical cost in the nation. Fourth, the capstone paper presented data related to risk factors for the population in the state of West Virginia. This data illustrated the socioeconomic disparities that put the population at risk for diabetes. And finally the capstone evaluated the use of SMA health care delivery model as a mechanism to address patients' access to quality diabetic care.

\section{Advanced Nursing Practice}

The last element of the DNP essentials was met in the following way. The SMA quality improvement project was implemented in northern West Virginia. Before the implementation of the quality improvement project a systematic assessment of the diabetes problem was conducted and outlined the cultural risk factors for the West Virginia population.

Second, The SMA was implemented and its outcomes were evaluated by using evidence- 
based measures. In order to implement the SMA quality improvement project community relationships were established with other clinical leaders. The program also enabled the nurse leader and the SMA support staff to develop a stronger patient-to-provider relationship. These relationships and partnerships facilitated the positive outcomes of the SMA as illustrated in this paper. The SMA quality improvement project demonstrated that the nurse leader demonstrated critical thinking judgement, systems thinking, and accountability in the project design and its evaluation. This capstone's success can be used as for other professional nurses as guide to achieve excellence in nursing practice. This capstone also educates participants of the SMA by empowering them to help them decrease diabetic complications. Finally, the nurse leader used analytical skills to evaluate the project.

\section{Conclusion}

Patients with diabetes, through the quality improvement project, have the opportunity to have an increased quality of life, decreased disease burden, and a natural support group to be built among the patients. By using a team approach and planned interactions via the SMA, patient self-management is strengthened with improved use of community resources and electronic information systems. The overall goal of the SMA for patients with diabetes is to improve access to care, improve adherence to the ADA standards of care, and increase patient and staff satisfaction with the health care delivery. For the medical director and office manager, this process will potentially decrease waiting lists, improve patient compliance, and patient satisfaction. After the first two groups were implemented and outcomes showed positive results, it is anticipated that the endocrinology office will continue to support the SMA. The success of 
the quality improvement project coupled with continued support will allow for the opportunity for the SMA format to be applied to patients with other chronic disease problems as well. 


\section{Reference}

American Association of Colleges of Nursing (2006). The essentials of doctoral education for advanced nursing practice. Retrieved from www.aacn nche.edu

American Diabetes Association (2013). Fast facts data and statistics about diabetes. Retrieved from http://professional.diabetes.org/admin/UserFiles/0\%20\%20Sean/FastFacts\%20March\%202013.pdf

American Diabetes Association (2014). Standards of Medical care in Diabetes 2014, retrieved from http://care.diabetesjournals.org/content/37/Supplement 1/S14.extract

American Diabetes Association (2016). Standards of Medical care in Diabetes 2016, retrieved from http://care.diabetesjournals.org/site/misc/2016-Standards-of-Care.pdf

Aschner, P.J., \& Ruiz, A.J., (2012). Metabolic Memory for Vascular Disease in Diabetes. Diabetes Technology \& Therapeutics, 14, 68-74. DOI: 10.1089/dia.2012.0012

Beck, A., Scott, J., Williams, P., Robertson, B., Jackson, D., \& Gade, G. (1997). A randomized trial of group outpatient visits for chronically ill older HMO members: The Cooperative Health Care Clinic. Journal America Geriatric Society,45, 543-549.

Bangalore, S., Kamalakkannan, G., Parkar, S., \& Messerli F. (2007). Fixed-dose combinations improve medication compliance: A Meta-Analysis. The American Journal of Medicine, 8, 713-719.

Borus, J. S., \& Laffel, L. (2010). Adherence challenges in the management of type 1 diabetes in adolescents: prevention and intervention. Current Opinion in Pediatrics, 22(4), 405-411. http://doi.org/10.1097/MOP.0b013e32833a46a7

Bronson, D., \& Maxwell, R. (2004). Shared medical appointments: Increasing patient access without increasing physician hours. Cleveland Clinic Journal of Medicine, 71, 369-377. 
Brower, A. (2009). Shared medical appointments. Modern Medicine network rnweb.com/sharedappt, 28-31.

Case, A., \& Deaton, A. (2015).The Untold Story: Why Middle-Aged White People Are Dying At Higher Rates www.pnas.org/lookup/suppl/doi:10. 1073/pnas.1518393112//DCSupplemental.

Centers for Disease Control and Prevention. (2014). National Diabetes Statistics Report: Estimates of Diabetes and Its Burden in the United States, 2014. Atlanta, GA: U.S. Department of Health and Human Services; 2014.

Centers for Disease Control and Prevention (CDC). (2011). National Diabetes Fact Sheet, 2011 Washington, DC: U.S. Government Printing Office. Retrieved July, 2013 from http://www.cdc.gov/obesity/data/trends.html.

Centers for Disease Control and Prevention. Diabetes Report Card 2012. Atlanta, GA: Centers for Disease Control and Prevention, US Department of Health and Human Services; 2012.

Clancy, D. E., Brown, S. B., Magruder, K. M., \& Huang, P. (2003). Group visits in medically and economically disadvantaged patients with diabetes and their relationships to clinical outcomes. Top Health Inf Manage, 24, 8-14.

Clancy, D. E., Cope, D. W., Magruder, K. M., Huang, P., Salter, K. H., \& Fields, A. W. (2003). Evaluating group visits in an uninsured or inadequately insured patient population with uncontrolled diabetes. Diabetes Educ, 29, 292-302.

Clancy, D. E., Dismuke, C. E., Magruder, K. M., Simpson, K. N., \& Bradford, D. (2008). Do diabetes group visits lead to lower medical care charges? Am J Manag Care, 14, 39-44. doi: 6968 [pii] 
Clancy, D. E., Huang, P., Okonofua, E., Yeager, D., \& Magruder, K. M. (2007). Group visits: promoting adherence to diabetes guidelines. J Gen Intern Med, 22, 620-624. doi: $10.1007 / \mathrm{s} 11606-007-0150-3$

Clancy, D. E., Yeager, D. E., Huang, P., \& Magruder, K. M. (2007). Further evaluating the acceptability of group visits in an uninsured or inadequately insured patient population with uncontrolled diabetes. Diabetes Educ, 33(2), 309-314. doi: 33/2/309 [pii] $10.1177 / 0145721707299266$

Coleman, K., Austin, B. T., Brach, C., \& Wagner, E. H. (2009). Evidence on the chronic care model in the new millennium. Health Affairs, 28, 175-185 doi: $10.1377 /$ hlthaff.28.1.75

Coyne, C., Popescu, C., \& Friend, D. (2006). Social and cultural factors influencing health in Southern West Virginia: A qualitative study. Preventing Chronic Disease: Public Health Research, Practice and Policy. 3, 1-8.

Cramer, J.A., Benedict, A., Muszbeck, N., Keskinaslan, A. \& Khan, Z. M. (2008). The significance of compliance and persistence in the treatment of diabetes, hypertension and dyslipidaemia: a review. Internal Journal of Clinical Practice, 62, doi: 10.1111/j.17421241.2007.01630.x

Dickman K., Pintz, C., \& Gold, K. (2012). Behavior changes in patients with diabetes and hypertension after experiencing shared medical appointments. Journal American Academy Nurse Practice; 24,43-51.

Dontje, K., \& Forrest, K. (2011). Implementing group visits: Are they effective to improve diabetes self-management outcomes? Journal Nurse Pracice, 7,571-577.

Dubois, R. W., Chawla, A. J., Neslusan, C. A., Smith, M. W., \& Wade, S. (2000). Explaining drug spending trends: Does perception match reality? Health Affairs, 19(2), 231-9. 
Retrieved from http://search.proquest.com/docview/204638069?accountid=2837

Edelman, D. McDuffiew, J. R. Oddone, E., Gierisch, J. M., \& Williams, J. W. (2010). Medical Clinics Versus Usual Care for patients with both diabetes and hypertension. Annals of Internal Medicine, 152,689-686.

Edelman, D., McDuffie, J. R., Oddone, E., Gierisch, J. M., Nagi, A., Williams, J. W. (2112). Shared Medical Appointments for Chronic Medical Conditions: A Systematic Review. VAESP Project\#09-010.

Edelman, D., Gierisch, J. M., McDuffie, J. R., Oddone, E., Williams, J. W. (2014). Shared Medical Appointments for Patients with Diabetes Mellitus: A Systematic Review General Internal Medicine, 30(1):99-106. DOI: 10.1007/s11606-014-2978-7

Group Health Research Institute (2014). Improving chronic illness the chronic care model Retrieved from modelhttp://www.improvingchroniccare.org/index.php?p=Model Elements\&s=18

Gutierrez, N. Gimpel, N. E. Dallo, F.J. Foster, B. M. \& Ohagi, E. J. (2011). Shared medical appointments in a residency clinic: An exploratory study among hispanics with diabetes, American Journal of Managed Care vol. 17, 212-214

Health Insurance Portability and Accountability Act (HIPAA) (1996). Of 1996 Public Law 104191, 104th Congress. Retrieved from: http://www.hhs.gov/ocr/privacy/ hipaa/administrative/statute/hipaastatutepdf.pdf

Herman, W. H. (2013). The economic costs of diabetes: Is it time for a new treatment paradigm? Diabetes Care vol. 36 no. 4 775-776 doi: 10.2337/dc13- 0270

Hiidenhovi, H., Laippala, P., \& Nojonen , K. (2001). Development of a patient-oriented instrument to measure service quality in outpatient departments. Journal of Advanced Nursing . 34, 696-705. 
Housden, L. Wong, S, Dawes, M. (2013). Effectiveness of group medical visits for improving diabetes care: a systematic review and meda-analysis. Canadian Medical Association Journal. DOI: 10,1503/cmj,130053.

Huttlinger, K.W., \& Purnell, L. D. (2008). People of Appalachian heritage. (p.95-112).

Images of the Chronic Care Model retrieved from https://www.google.com/search?q=chronic+care+model+wagner\&rlz

Institute of Medicine, (2001). Crossing the quality chasm: A new health system for the $21 \mathrm{st}$ century. Retrieved from: http://www.nap.edu/books/0309072808/html/

Kirkman, M. S., Williams, S. R., Carffrey, H. H., Marrero, D. G.( 2002). Impact of a Program to improve adherence to diabetes guidelines by primary care physicians. Diabetes Care, 25 1946-1951. doi:10.2337

Kirsh, S., Watt, S., Pascuzzi, K., O’Day, M., Davison, D., Strauss, G., Kern, E. O., \& Aron, D. (2007). Shared Medical appointments based on the chronic care model: a quality improvement project to address the challenges of patients with diabetes with high cardiovascular risk. Qual Saf Health Care; 16,349-353. doi:10.1136/qshc.2006.019158

LeRoy, L., Shoemaker, S. J., Levin, J.S.,Weschler, C. A., Schaefer, J. \& Genevro, J. L.(2014). Self- management support resources for nurse practitioners and clinical teams. Journal for Nurse Practitioners, 10, 88-93. doi.org/10.1016/j.nurpra.2013.08.024

Mallow, J. A., Theeke, L. A., Whetsel. T., \& Barnes, E. R. (2013). Diabetes group medical visits and outcomes of care in low-income, rural, uninsured persons. Open Journal of Nursing, 3, 314-322. Retrieved from http://www.scirp.org/journal/ojn.

Martin, L. R., Williams, S. L., Haskard, K. B.(2005). The challenge of patient adherence. 
Therapeutics and Clinical Risk Management 1(3) 189.-199.

Mazze, R. S., Strock, E., Peterson, K., McClave, C. R., Meszaros, J. F., Leigh, C., Kummer, M. (1994). Staged diabetes management toward an integrated model of diabetes care. Diabetes Care 17, 56-66.

National Committee for Quality Assurance. What is HEDIS? HEIDIS and quality compass. Retrieved from http://.ncqa.org/tabid/187

Noffsinger, E., Sawyer, D. R., Scott, J. (2003). Group medical visits: a glimpse into the future? Patient care for the nurse practitioner. Retrieved from http://web.b.ebscohost.com.www.libproxy.wvu.edu/ehost/detail/detail?vid=19\&sid=151b 0a9e-ec53-43f9-834e-

Phillips, L. S., Ziemer, D. C., Doyle, J. P., Barnes, C. S., Kolm, P., Branch, W. T.,... Watkins, C. (2005). Endocrinologist-Supported Intervention Aimed at Providers Improves Diabetes Management in a Primary Care Site. Diabetes Care,28, 2352-2360. doi: 10.2337

Piette, J. D, Heisler, M, Wagner, T. H. (2004). Problems paying out-of-pocket medication costs among older adults with diabetes. Diabetes Care. 27(2):384-91.

Quinones, A.R., Richardson, J., Freeman, M., O’Neil, M.E., \& Kansagara, D. (2012). Group visits focusing on education for the management of chronic conditions in adults; A systematic review. VA- ESP Project \# 05-225.

Renders, C., M., Valk, G.D., Griffin, S. J., Wagner, E., Eijk, J. T., Assendelft, W. J. (2002). Interventions to improve the management of diabetes mellitus in primary care, outpatient, and community settings, Cochrane Database of Systematic Reviews no. 1 CD001481. DOI: 10.1002/14651858.CD001481

Ridge, T. (2012). Shared medical appointments in diabetes care a literature review. Diabetes spectrum $25,72-75$. 
Rizza, R. A., Vigersky, R. A., Rodbard, H. W., Ladenson, P. W., Young, W. F., Kahn, R., \& Hogan, P. F. (2003). A model to determine workforce needs for endocrinologists in the United States until 2020. Diabetes Care 26,1545-1552.

Robert Wood Johnson. (2012). County health rankings \& roadmaps a healthier nation, county by county. Retrieved from http://www.countyhealthrankings.org/sites/default/files/states/CHR2013 WV 0.pdf

Sanchez, I. (2011). Implementation of a diabetes self-management education program in primary care for adults using shared medical appointment. The Diabetes Educator, 3,381-391. Doi:10.1177/0145721711401667

Schenck, A., Andrulis, D.P., Bartram, J., Booske, B, C., Coburn, A., Devlin, L.,...Milder, S (2013). American's health ranking United Health Foundation, a call to action for individuals and their communities, 2013 edition. United Health Foundation, Retrieved from www.americanshealthrankings.org

Scottish Intercollegiate Guidelines Network (SIGN) (2010). Management of diabetes. A national clinical guidelines. Edinburgh (Scotland): Scottish Intercollegiate Guidelines Network (SIGN); 170 p. (SIGN publication; no. 116). [759 references]. Retrieved from http://www.guideine.gov/popups/print View.aspx?id=16394

Shah, B. R., James, J. E., Lawton, C., Montada-Atin, T., Sigmond, M., Cauch-Dudek, K., \& Booth, G. L. (2009). Diabetes quality of care in academic endocrinology practice: a descriptive study. Canadian Journal of Diabetes. 33(3):150-155.

Sikon, A. \& Bronson, D. L. (2010). Shared Medical Appointments: Challenges and Opportunities. Annals of Internal Medicine, 152, 745-746.

Simmons, C., \& Kapustin, J. F. (2011). Diabetes group visits: An alternative to managing chronic disease outcomes. The Journal for Nurse Practitioners, 7, 671-679. 
doi:10.1016/j.nurpra.2010.12.002

Thacker, H. L., Maxwell, R., Saporito, J., \& Bronson, D. (2005). Shared medical appointments: facilitating interdisciplinary care for midlife women. Journal Womens Health (Larchmt), 14, 867-70.

Trento, M., Passera, P., Borgo, E., Tomalini, M., Bajardi, M., Pomero, F.,...Porta, M. ( 2001). Group visits improved metabolic control in type 2 diabetes. Diabetes Care, 24, 9951000.

Trento, M., Passera, P., Bajardi, M., Tomalino, M., Grassi, G., Borgo, E. (2002). Lifestyle intervention by group care prevents deterioration of Type II diabetes: a 4-year randomized controlled clinical trial. Diabetologia, 45, 1231-1239. doi: 10.1007/s00125002-0904-8

Trento, M., Passera, P., Borgo, E., Tomalino, M., Bajardi, M.,Cavallo,F., Porta, M.,(2004). A 5-Year Randomized Controlled Study of Learning, Problem Solving Ability, and Quality of Life Modifications in People With Type 2 Diabetes Managed by Group Care. Diabetes Care, 27, 670-675.

Vigersky, R. A., Fish, L., Hogan, P., Stewart, A., Kutler, S., P., Ladenson, P. W., ... Hupart, K. H., (2014). The clinical endocrinology workforce: Current status and future projections of supply and demand. J Clin Endocrinol Metab, (9):3112-3121 doi: $10.1210 /$ jc. $2014-2257$.

Wagner, E. H., Austin, B.T., Davis, C., Hindmarsh, M., Schaefer, J., Bonomi, A. (2001). Improving chronic illness care: translating evidence into action. Health Aff. 6, 64-78.

Wagner, E. H., Grothaus, L. C., Sandhu, N., Galvin, M. S., McGregor, M., Artz, K. (2001). Chronic care clinics for diabetes in primary care: a system-wide randomized trial. Diabetes Care, 24, 695-700. 
Watts, S. A., Strauss, G. J., Pascuzzi, K., O’Day, M., Young, K., Aron, D. C., Kirsh, S. R. (2015). Shared medical appointments for patients with diabetes: Glycemic reduction in high-risk patients. Journal of the American Association of Nurse Practitioners 27 450456

West Virginia Department of Health \& Human Resources, (2013). West Virginia Behavioral Health Epidemiological Profile. Retrieved from http://www.dhhr.wv.gov/bhhf/resources/ Documents/2013_State_Profile.pdf

West Virginia Department of Health and Human Resources Health Statistic Center, (2012). Diabetes and Health Equity in West Virginia: A review. HSC statistical Brief No. 28. Retrieved from http://www.wvdhhr. Org/bph/hsc/

West Virginia Department of Health \& Human Resources, (2012). West Virginia State Health Profile Shaping Safe and healthy communities. Retrieved from http://www.dhhr.wv.gov/publichealthquality/statepublichealthassessment/Documents/201 2\%20State\%20Health\%20Profile\%20Final\%20May\%202013.pdf

Wheeling Hospital Quality Management Plan/Care Management - Utilization Review Plan (2014 ). Retrieved from http://intranet/polproc/polproc.aspx?h=\&p=3694 


\section{Appendix A \\ Wheeling Hospital \\ Dr. Bunner Endocrinology \\ Shared Medical Visit HIPAA Notice}

During a shared medical visit, it is possible that some of my individually identifiable health information will be disclosed. For example, it might be assumed that everyone attending the group visit has the same medical condition. I have read and I understand the following statements about my rights:

- I have the option to be seen individually

- I am not required to sign this form to receive healthcare treatment

- Discussions may occur regarding individually identifiable health information during the shared medical visit

- It is possible that the information that is used or disclosed in a shared medical visit may be redisclosed by other participants in the visit

- I have been notified of this potential disclosure, and I voluntarily wish to participate in the shared medical visit

This Shared Medical Visit HIPAA Notice Regarding Use and Disclosure supplements the Notice of Privacy Practice originally provided to me, a copy of which is on file with my healthcare provider.

Date 


\title{
Sample Invitation Letter to Patients
}

\section{APPENDIX B}

\author{
Wheeling Hospital \\ Dr. Bunner Endocrinology \\ $5816^{\text {th }}$ Street Wheeling, WV 26003
}

Date

Dear

I would like to invite you to join a new type of medical visit I am starting to help my patients who would like more information to help them manage their diabetes. It's called a shared medical visit, or group visit, and, in this type of visit, you and about 9 other patients will meet at our office to get information about diabetes and to also receive a private medical exam from me.

Studies have shown that taking part in a shared medical visit can improve the way you manage your condition and can also improve your health.

Of course, you have the option of being seen individually without changing our relationship in any way. Patients who choose to join a shared medical visit can also continue to be seen individually and may stop attending group visits at any time.

Because this is a new type of visit, we are only inviting a small number of patients. If you choose to join this group visit, you would:

- Attend a ninety minute group visit with me in our office. As a group, we will talk about both medical and non-medical issues that are related to your health condition

- Pay your standard co-pay or office-visit fee, just as you would do with a regular office visit

- Want to keep in mind that it is possible for personal health information, such as your diagnosis or related health problems, to be disclosed at this type of visit; you will be asked to sign a HIPAA disclaimer to accept this before the visit

Our shared medical visit will be held on of anticipated group) patients join in this group. If you would like to attend, please call We plan to have __ to (size (Coordinator name) at until . This visit will be held at our office from Snacks will be provided.

If you have any questions, please call Dr. Bunner's office at 304-243-6410 or go to our Web site, www._wheelinghospital. I think that you would enjoy and learn from this session and hope to see you there.

Sincerely, 
SMA Flyer

\section{APPENDIX C}

\section{Wheeling Hospital \\ Dr. Bunner Endocrinology}

We are now pleased to offer shared medical visits for our patients.

A shared medical visit is a way for our healthcare providers to meet with a group of patients with diabetes at one time. It gives patients the chance to meet with their healthcare provider, as well as health educators and support staff, and learn how other patients are managing the same condition and overcoming similar health-related challenges.

Key benefits include:

- Better access to your healthcare provider

- A regularly scheduled visit

- Getting to know others with similar issues

- Improved health and increased satisfaction

If you would like to learn more about joining our next shared medical visit, please ask your healthcare provider or a member of our office staff for additional information call 304 243-6410. 


\section{APPENDIX D}

\section{SMA Flow Chart}

\section{A total of 120 Minutes}

\section{Groub one. 90 Minutes (6-7 Patients) popPatients)}

\section{Groub Two. 90 Mlinutes ( 6-8 Patients)}

\begin{tabular}{|c|c|c|c|}
\hline $\begin{array}{c}\text { One-on-One } \\
\text { Provider Time }\end{array}$ & $\begin{array}{c}\text { Guest Speaker } \\
\text { Time }\end{array}$ & $\begin{array}{c}\text { Motivational } \\
\text { Education }\end{array}$ & $\begin{array}{l}\text { One-on-One } \\
\text { Provider Time }\end{array}$ \\
\hline $\mathbf{3 0}$ Minutes & $\mathbf{3 0}$ Minutes & $\mathbf{3 0}$ Minutes & $\mathbf{3 0}$ Minutes \\
\hline
\end{tabular}


APPENDIX E

\section{Diabetic Flow Sheet}

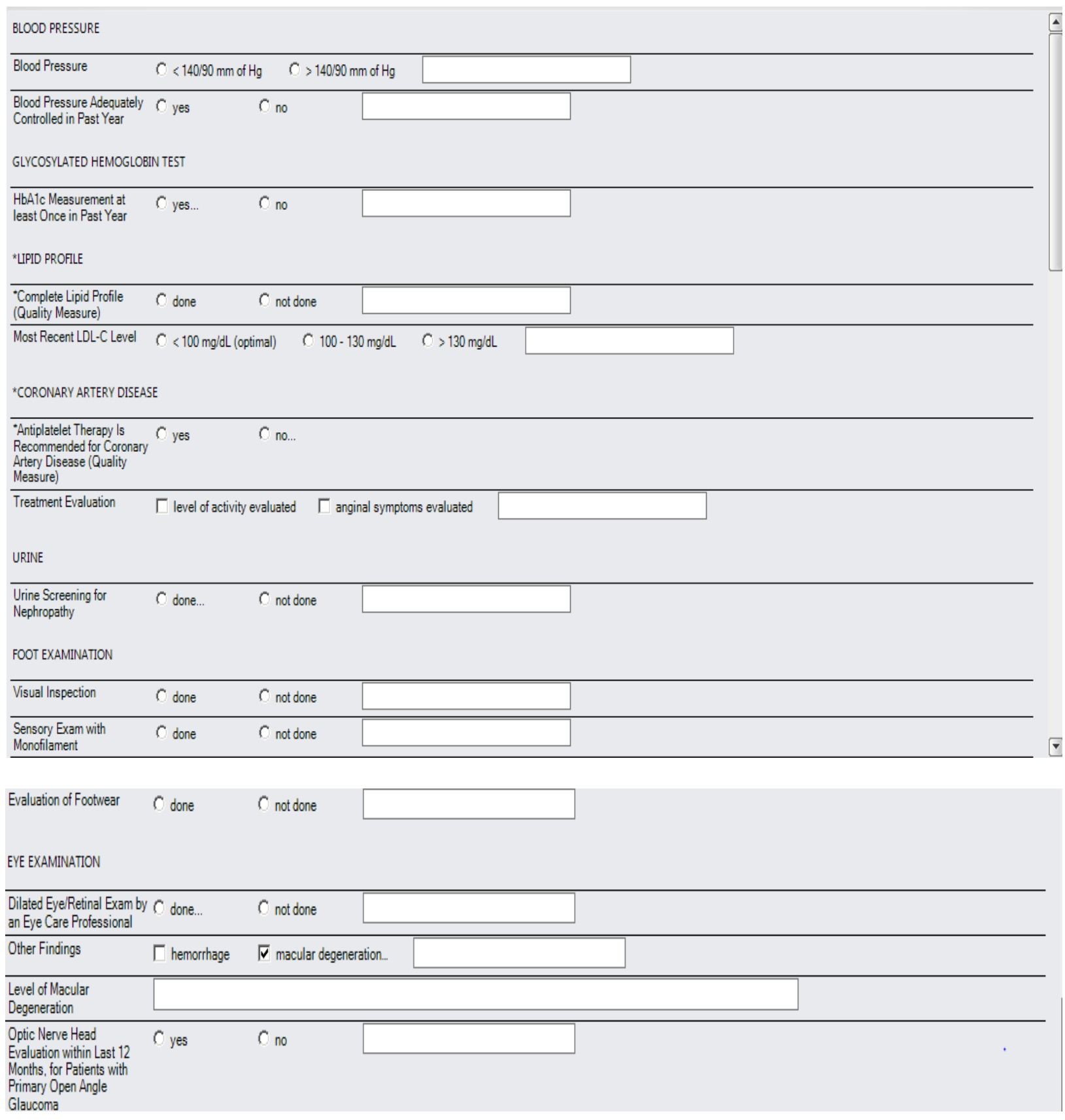




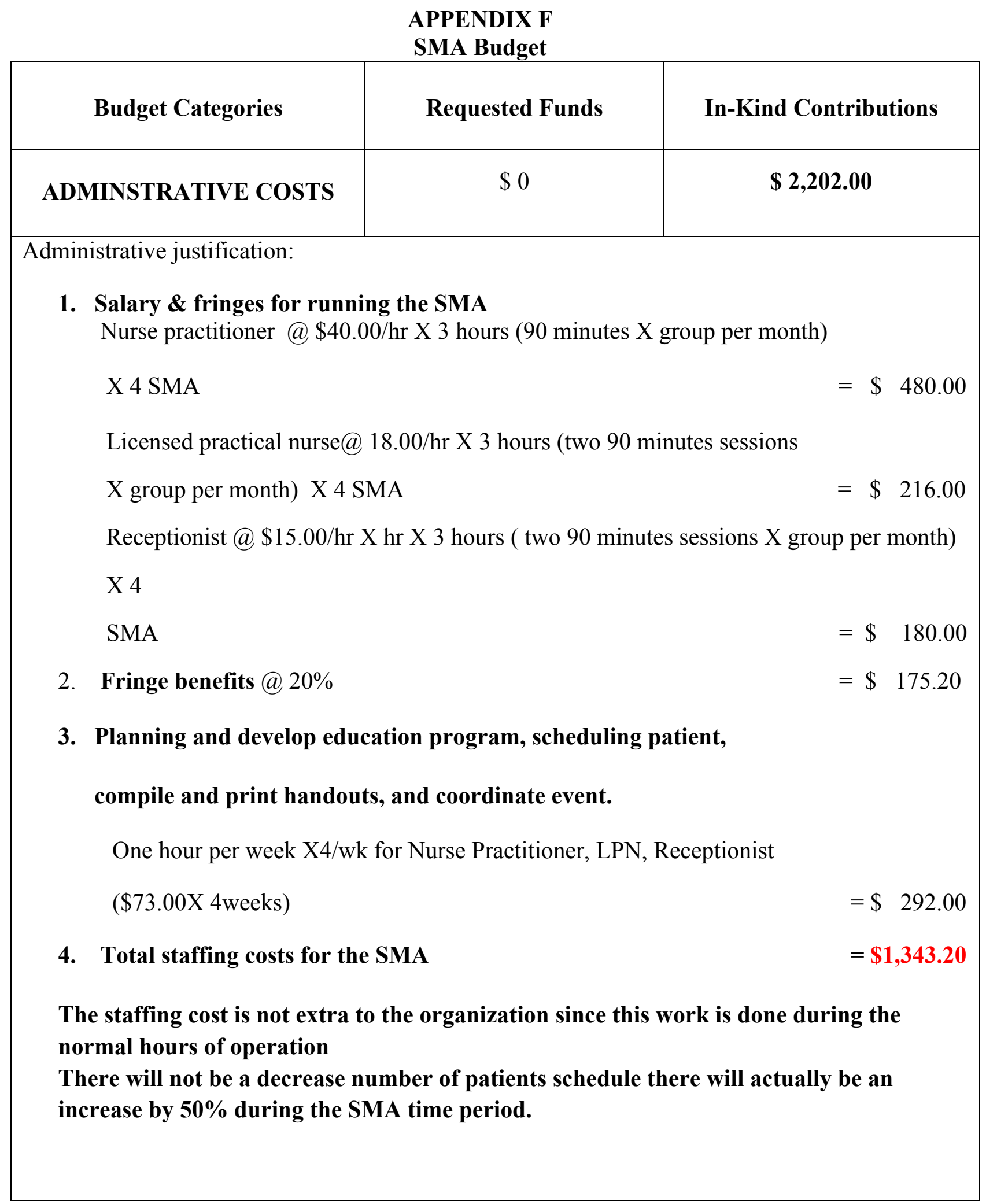




\begin{tabular}{|c|c|c|}
\hline $\begin{array}{l}\text { EDUCATIONAL } \\
\text { MATERIALS/ INCENTIVES }\end{array}$ & $\$ 0$ & $\$ 221.90$ \\
\hline \multicolumn{3}{|c|}{ Educational Materials/Incentives justification: } \\
\hline \multicolumn{3}{|c|}{$\begin{array}{l}\text { Diabetes educational handouts free from http://www.NovoMedLink.com } \\
\text { Conference gift (tote bag) for participants }\end{array}$} \\
\hline $\begin{array}{l}\text { HOSPITALITY (food, room } \\
\text { rentals, etc.) }\end{array}$ & $\$ 200.00$ & $\$ 200.00$ \\
\hline \multicolumn{3}{|l|}{ Hospitality justification: } \\
\hline \multicolumn{3}{|l|}{ Conference Room no charge } \\
\hline \multicolumn{3}{|l|}{ Room set up no charge } \\
\hline \multicolumn{3}{|l|}{ Microphone, screen no charge } \\
\hline \multicolumn{3}{|l|}{ Light snack@\$50/day x 4 days } \\
\hline & & $=\$ 200.00$ \\
\hline Total & & $=\$ 200.00$ \\
\hline $\begin{array}{l}\text { PROJECT SUPPLIES (office } \\
\text { supplies, postage, printing, etc.) }\end{array}$ & $\$$ & $\$ 437.00$ \\
\hline \multicolumn{3}{|l|}{ Project supplies justification: } \\
\hline \multicolumn{2}{|c|}{24 notebooks @ \$12.00 each (binders, dividers, paper, ink for handouts,) } & $=\$ 288.00$ \\
\hline \multicolumn{2}{|l|}{ In house printing } & $=\$ 100.00$ \\
\hline \multicolumn{3}{|c|}{ Postage mailing out letters of invitation to participants, PCP, referring specialist } \\
\hline 100 mailing pieces@ @ $\$ 0.49$ & & $=\$ \quad 49.00$ \\
\hline
\end{tabular}




\begin{tabular}{|c|c|c|}
\hline SPEAKER FEES & $\$ 0$ & $\$$ \\
\hline \multirow{2}{*}{\multicolumn{3}{|c|}{$\begin{array}{l}\text { Speaker fees justification: } \\
4 \text { speakers are part of the hospital's speakers bureau and there is no charge }\end{array}$}} \\
\hline & & \\
\hline \multicolumn{3}{|c|}{ Dr. Latus (nephrology) } \\
\hline \multicolumn{3}{|c|}{ Dr. Leeper (retina specialist) } \\
\hline \multicolumn{3}{|c|}{ Exercise Physiologist and Register dietitian from Howard Long Wellness Center } \\
\hline TOTALS & $\$ 200.00$ & $\$ 2,202.00$ \\
\hline
\end{tabular}


APPENDIX G

\title{
LETTER OF SUPPORT
}

\author{
(8) \\ WHEELING \\ HOSPITAL

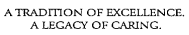

To whom it may concern:

I am writing on behalf of Amanda Wakim. I am very excited to have Amanda as a member of this practice and about her plans for shared medical visits. I feel this venture will significantly improve our patient care and patient satisfaction. I am anxious to implement this quality improvement measure and review with Amanda the outcomes.

Kind regards,

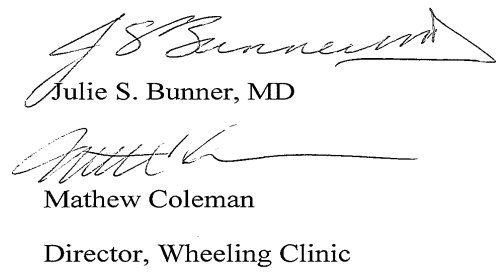

JULIE S. BUNNER, M.D 


\section{APPENDIX H}

SMART OBJECTIVES

Work Plan for Shared Medical Appointments

Project Goals: To provide Shared Medical Appointments for patients with type I and type II diabetes. The group appointments will consists of 12 to 15 patients. Evidence-based education for the patients, regarding diabetes care, prevention of complications and early detection of disease process, to reduce morbidity and mortality from diabetes will be included in the SMA. Two groups will attend 4 SMA sessions a month apart. Appointments will be 90 minutes long but the actual section will run for 120 minutes.

\begin{tabular}{|c|c|c|c|c|c|}
\hline $\begin{array}{ll}\text { - SHARED } & \text { Medical } \\
\text { Appointments } & \end{array}$ & Activities & $\begin{array}{l}\text { Projected } \\
\text { Completion } \\
\text { Date }\end{array}$ & $\begin{array}{l}\text { Projected } \\
\text { Number of People } \\
\text { Reached }\end{array}$ & $\begin{array}{l}\text { Organization(s)/ } \\
\text { Partner(s) } \\
\text { collaborating with to } \\
\text { conduct activity }\end{array}$ & $\begin{array}{l}\text { Evaluation } \\
\text { Plan } \\
\text { (Describe } \\
\text { measures used } \\
\text { to assess } \\
\text { satisfaction, } \\
\text { project } \\
\text { outcomes, } \\
\text { benefits of } \\
\text { activities, etc.) }\end{array}$ \\
\hline $\begin{array}{l}\text { By August 7, } 2014 \text { Will obtain } \\
\text { approval from the endocrinology } \\
\text { office for the SMA }\end{array}$ & $\begin{array}{l}\text { Will meet with Dr. Bunner } \\
\text { and the Director of the Clinic to } \\
\text { obtain approval for the SMA }\end{array}$ & $\begin{array}{l}\text { August 30, } \\
2013\end{array}$ & $\begin{array}{l}\text { Endocrinologist ( } \\
\text { Dr. Bunner), } \\
\text { Director of the } \\
\text { clinic ( Mathew } \\
\text { Coleman) Nurse } \\
\text { leader( Amanda } \\
\text { Wakim) }\end{array}$ & $\begin{array}{l}\text { Faith based } \\
\text { Organization and } \\
\text { endocrinology office }\end{array}$ & $\begin{array}{l}\text { Assure Dr. } \\
\text { Bunner giver } \\
\text { approval as } \\
\text { well as the } \\
\text { Director of the } \\
\text { clinic by } \\
\text { evidence of a } \\
\text { letter of } \\
\text { support. }\end{array}$ \\
\hline
\end{tabular}




\begin{tabular}{|c|c|c|c|c|c|}
\hline $\begin{array}{l}\text { By December } 15,2014 \\
\text { Complete Capstone proposal for } \\
\text { SMA quality improvement } \\
\text { intervention. } \\
\text { Obtain final approval for the } \\
\text { quality improvement project } \\
\text { from the endocrinologist and } \\
\text { office manager }\end{array}$ & $\begin{array}{l}\text { The submit proposal to } \\
\text { Capstone Committee } \\
\text { Meet in person with office } \\
\text { manager and Medical } \\
\text { Director after Capstone } \\
\text { committee approves the } \\
\text { proposal }\end{array}$ & December $15^{\text {th }}$ & $\begin{array}{l}\text { WV University } \\
\text { DNP Capstone } \\
\text { Committee }\end{array}$ & $\begin{array}{l}\text { WVSON and DNP } \\
\text { student } \\
\text { Faith based } \\
\text { Organization and } \\
\text { endocrinology office }\end{array}$ & $\begin{array}{l}\text { Proposal } \\
\text { accepted and } \\
\text { ready for IRB } \\
\text { approval }\end{array}$ \\
\hline & & & 3 & & \\
\hline $\begin{array}{l}\text { By January } 15,2015 \text { the IRB } \\
\text { process will be implemented. }\end{array}$ & $\begin{array}{l}\text { * Meet with project Chair to } \\
\text { evaluate process change. } \\
\text { *Discuss timeline changes with } \\
\text { Chair. } \\
\text { * Send proposal to clinical expert } \\
\text { for review. } \\
\text { *Revise proposal as indicated } \\
\text { Begin IRB process }\end{array}$ & $\begin{array}{l}\text { Jan 15.30, } \\
2015\end{array}$ & 4 & $\begin{array}{l}\text { Chair/committee } \\
\text { IRB }\end{array}$ & $\begin{array}{l}\text { Emails and } \\
\text { phone } \\
\text { meetings to } \\
\text { evaluate } \\
\text { readiness of } \\
\text { proposal and } \\
\text { revise if } \\
\text { needed. } \\
\text { Forms for IRB } \\
\text { will be } \\
\text { completed and } \\
\text { reviewed by } \\
\text { Chair and } \\
\text { committee. }\end{array}$ \\
\hline
\end{tabular}




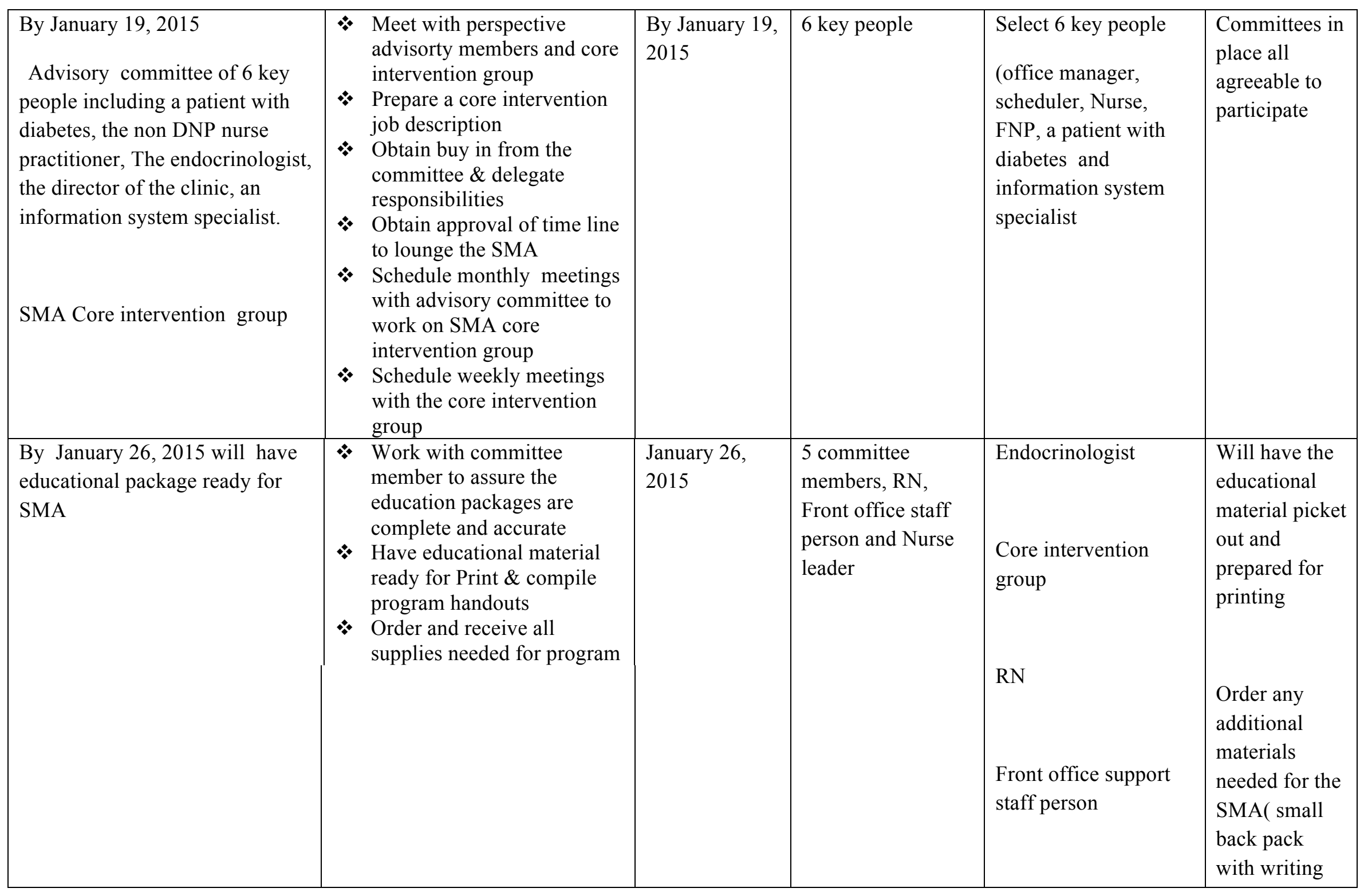




\begin{tabular}{|c|c|c|c|c|c|}
\hline & & & & Nurse Leader & $\begin{array}{l}\text { tablet, pen, } \\
\text { bottle water } \\
\text { dispenser \& } \\
\text { other } \\
\text { promotional } \\
\text { material) }\end{array}$ \\
\hline $\begin{array}{l}\text { January } 19 \text { through January } \\
26 \text { invitation letters to } \\
\text { current patients and a Press } \\
\text { release to , PCPs, local } \\
\text { hospitals and media will be } \\
\text { send out. }\end{array}$ & $\begin{array}{l}\text { Front office will mail out } \\
\text { letters for the SMA } \\
\text { invitation to all AF Female } \\
\text { patients in the practice. The } \\
\text { invitation will include a } \\
\text { description of how the } \\
\text { program works. } \\
\text { Mail a press release letter to } \\
\text { all to all the PCP and local } \\
\text { hospitals }\end{array}$ & January 26 & $\begin{array}{l}\text { From the } \\
\text { endocrinology } \\
\text { practice will recruit } \\
\text { a least } 75 \text { patients } \\
\text { that meet the SMA } \\
\text { criteria }\end{array}$ & $\begin{array}{l}\text { Front office } \\
\text { Project Director } \\
\text { Steering committee } \\
\text { Faith Based } \\
\text { Organization( public } \\
\text { relations staff) and } \\
\text { Ohio County Media }\end{array}$ & $\begin{array}{l}\text { All } \\
\text { prespective } \\
\text { patients will } \\
\text { be informed } \\
\text { via letter of } \\
\text { invitation } \\
\text { askingthem to } \\
\text { call to } \\
\text { schedule } \\
\text { SMA. } \\
\text { The press } \\
\text { release will } \\
\text { help to } \\
\text { educate others } \\
\text { regarding the } \\
\text { new inititive } \\
\text { and how it } \\
\text { works. }\end{array}$ \\
\hline
\end{tabular}




\begin{tabular}{|c|c|c|c|c|c|}
\hline $\begin{array}{l}\text { By February } 9,2015 \\
\text { Patients are schedule for } 4 \\
\text { SMA sessions to begin on } \\
\text { February } 18 \text { and } 19,2014 \text { at } \\
\text { 2:00 to } 4: 00 \text { ( they will } \\
\text { continue to meet monthly on } \\
\text { the third week of the month } \\
\text { times } 4 \text { months } \\
\text { reminder calls will be made } \\
\text { to patients regarding SMA }\end{array}$ & $\begin{array}{l}\text { Front office will begin to } \\
\text { schedule patients for the first } \\
\text { pilot SMA clinic. }\end{array}$ & February 9 & 12 to 15 patients & $\begin{array}{l}\text { Office manager and } \\
\text { scheduler and FNP }\end{array}$ & $\begin{array}{l}\text { The SMA } \\
\text { clinic will } \\
\text { have } 12 \text { to } 15 \\
\text { patients } \\
\text { schedule. }\end{array}$ \\
\hline $\begin{array}{l}\text { February 16, } 2015 \text { Make sure all } \\
\text { the equipment, templates, } \\
\text { educational material is ready } \\
\text { Refreshments order for the } \\
\text { SMA clinic } \\
\text { Conference room is ready } \\
\text { Name tags are made }\end{array}$ & $\begin{array}{l}\text { Schedule the first SMA } \\
\text { meeting. } \\
\text { SMA patient's } \\
\text { Confidentiality document is } \\
\text { ready } \\
\text { Make sure the conference } \\
\text { room is set up } \\
\text { Make sure the patients' } \\
\text { material packages are ready } \\
\text { Name tags are made } \\
\text { Refreshments are order and } \\
\text { set up in break room } \\
\text { Pre and post test on lecture } \\
\text { presentation is developed } \\
\text { and printed } \\
\text { SMA evaluation tool is } \\
\text { developed and printed }\end{array}$ & $\begin{array}{l}\text { February 16, } \\
2015\end{array}$ & $\begin{array}{l}\text { Two groups of } 12 \\
\text { to } 15 \text { patients }\end{array}$ & $\begin{array}{l}\text { Nurse Leader } \\
\text { Front office support } \\
\text { staff } \\
\text { Steering committee }\end{array}$ & $\begin{array}{l}\text { SMA patient's } \\
\text { Confidentialit } \\
\text { y document is } \\
\text { signed and } \\
\text { collected } \\
\text { The } \\
\text { conference } \\
\text { room was set } \\
\text { up in U shape } \\
\text { format } \\
\text { Power point } \\
\text { projector is } \\
\text { available and } \\
\text { working } \\
\text { educational } \\
\text { lecture is } \\
\text { prepared. }\end{array}$ \\
\hline
\end{tabular}




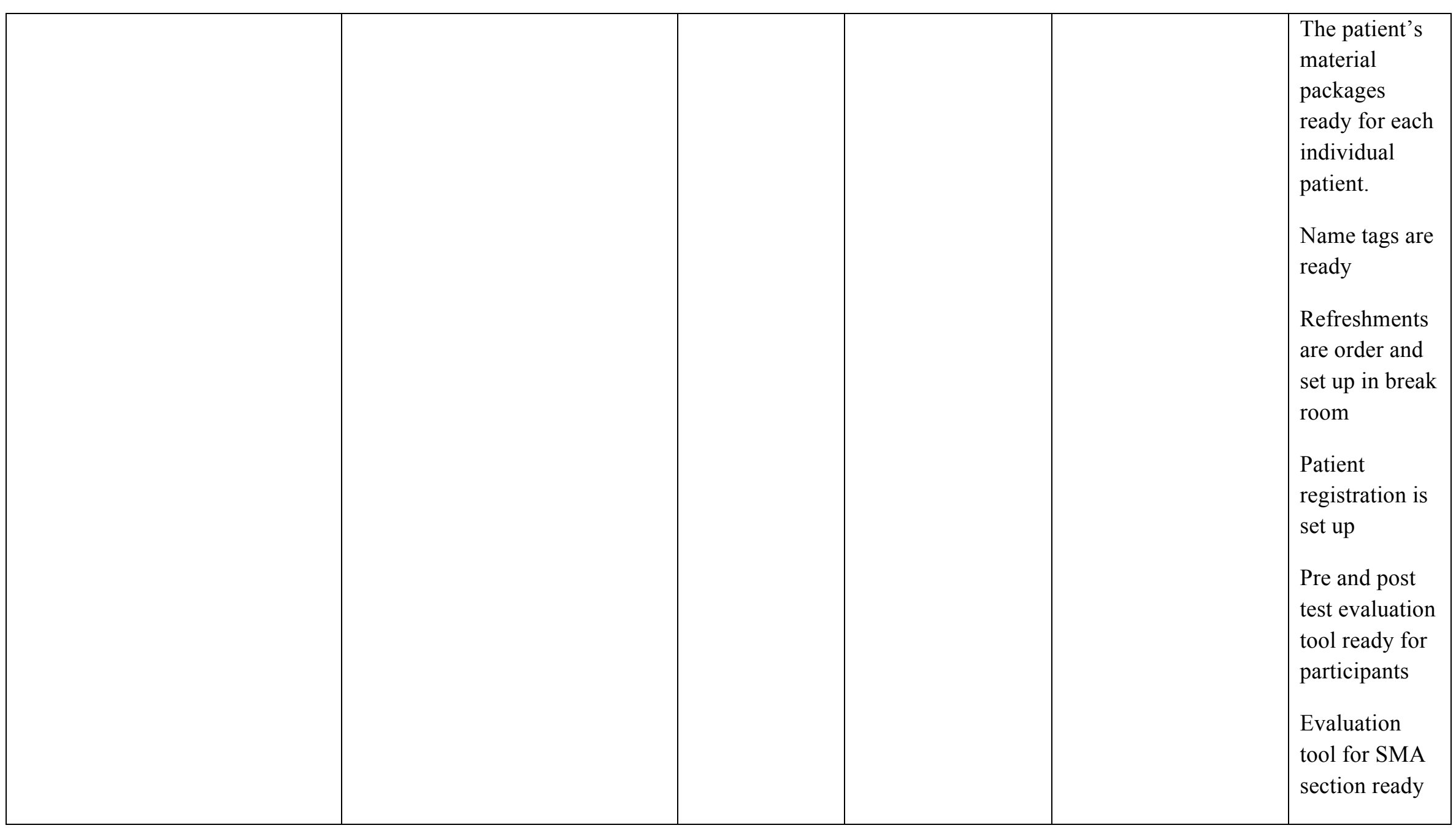




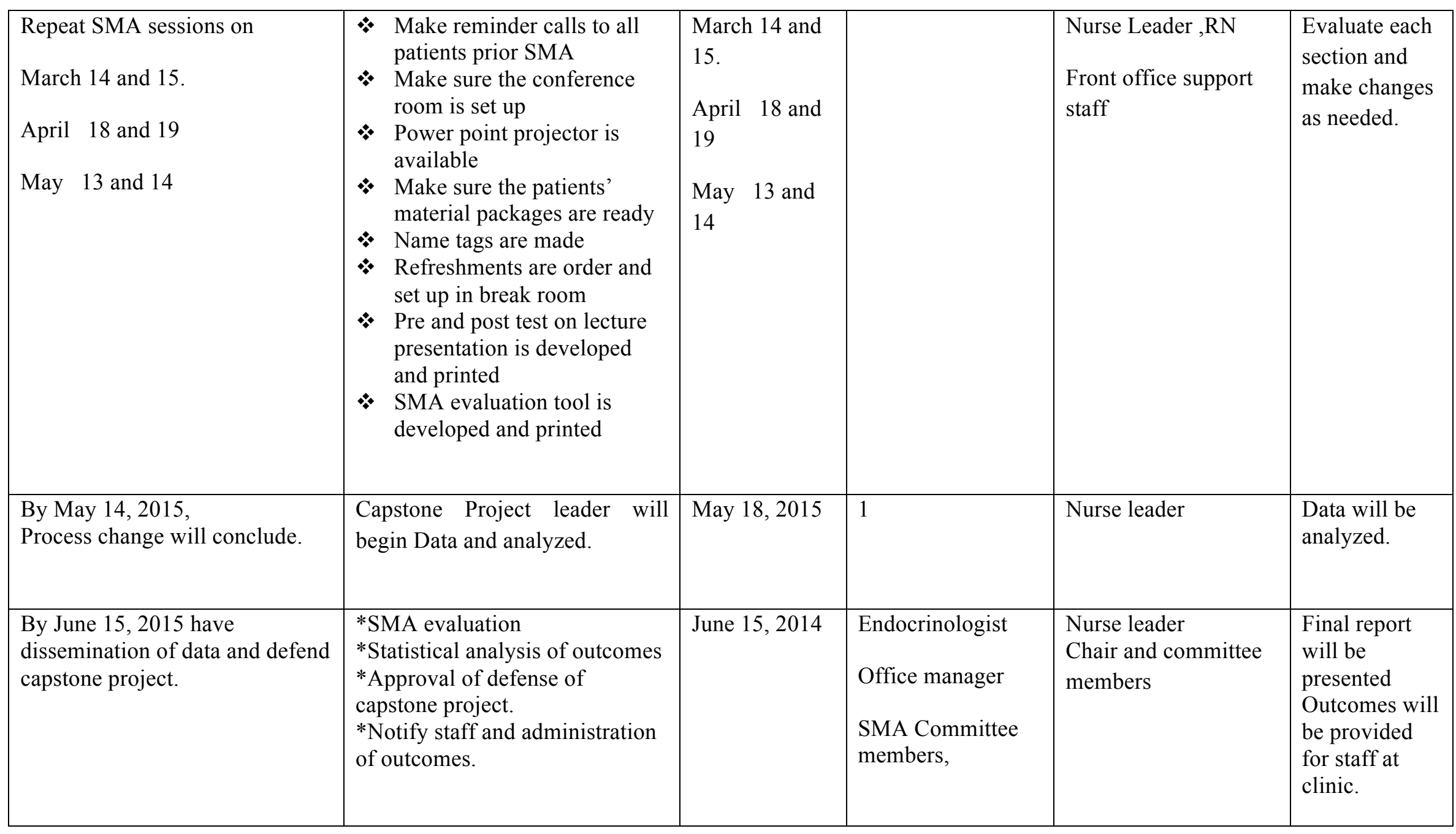


Running Head: ENDOCRINOLOGY SHARED MEDICAL APPOINTMENTS 102

\section{APPENDIX I}

Time Line

\begin{tabular}{|c|c|c|c|c|c|c|c|c|c|c|c|c|c|c|}
\hline Task & & & & 20 & & & & & & & & & & \\
\hline & May & Jun & Jul & Aug & Sep & Oct & Nov & Dec & Jan & Feb & Mar & Apr & May & Jun \\
\hline $\begin{array}{l}\text { Evaluate } \\
\text { problem } \\
\text { Discuss } \\
\text { timeline } \\
\text { Complete } \\
\text { Capstone } \\
\text { proposal } \\
\end{array}$ & & & & & & & & & & & & & & \\
\hline $\begin{array}{l}\text { Implement } \\
\text { IRB process } \\
\text { and obtain } \\
\text { approval of } \\
\text { capstone } \\
\text { project }\end{array}$ & & & & & & & & & & & & & & \\
\hline $\begin{array}{l}\text { Advisory and } \\
\text { intervention } \\
\text { core } \\
\text { committee pre } \\
\text { planning } \\
\text { Advertisement } \\
\text { Scheduling of } \\
\text { patients }\end{array}$ & & & & & & & & & & & & & & \\
\hline $\begin{array}{l}\text { Implement } \\
\text { The SMA } \\
\text { Base line } \\
\text { assessment } \\
\text { Post SAM } \\
\text { assessment }\end{array}$ & & & & & & & & & & & & & & \\
\hline $\begin{array}{l}\text { Data } \\
\text { collection and } \\
\text { analysis of } \\
\text { date } \\
\text { Evaluation of } \\
\text { change } \\
\text { project }\end{array}$ & & & & & & & & & & & & & & \\
\hline
\end{tabular}


Running Head: ENDOCRINOLOGY SHARED MEDICAL APPOINTMENTS 103

\section{Patient-Oriented Quality Instrument Assigned patient number}

\section{APPENDIX J}

Our mission is to improve service quality in our outpatient department. We are asking you to express your view of your current visit to the department by completing this questionnaire. Your answers are important to us and will be kept confidential.

$\begin{array}{lll}\begin{array}{l}\text { Please circle the number which best } \\ \text { Good Very Excellent } \\ \text { poor } \\ \text { provided you in the following items. } \\ \text { (Please grade these on a scale of 1-7, } \\ \text { only one number per question) }\end{array} & \begin{array}{c}\text { Extremely Very poor } \\ \text { describes the quality of care, the staff } \\ \text { good }\end{array} & \\ \end{array}$

1. You received information in advance about 1 2 3 $6 \quad 7$ the length of visit

2. Seen by staff at the appointed time

3. Professional skill of staff

4. Polite manners by staff

5. Service-mindedness of staff

6. Information on examination and test results

7. Information on medications and their effects

1

2

8. Information on treatment options

1

2

3

9. Information on probable outcomes of illness

$$
\begin{array}{ll}
6 & 7
\end{array}
$$

10. Protection of privacy 
Running Head: ENDOCRINOLOGY SHARED MEDICAL APPOINTMENTS

104

11. Usefulness in terms of examination and medical $6 \quad 7$

12

3

4

5

12. Overall success of the visit

1

2

3

4

5

What do you like best about the appointment?

What do you like least about the appointment?

Suggestions for improvement?

Thank you for completing our Survey! 


\title{
Running Head: ENDOCRINOLOGY SHARED MEDICAL APPOINTMENTS
}

\section{APPENDIX K}

RN, FNP-BC

Tampere 27/3 2015

Amanda Wakim

4 Linden Ave

Wheeling, WV 26003

Dear Amanda,

Thank you for Your kind letter dated 3/6/2015. I am glad to learn that You are working on the same topic I worked in an earlier phase of my life. Since those days $\mathrm{Dr}$ Laippala has died and myself have retired. The needs of patients are still there and so much more should be done for the quality of work at nursing and medicine.

Of course, you are free to utilize all the information You find and need in my publications and apply them to Your own work. My desire has only been and still is that if somebody use the information, she or he would cite the source.

I wish you strength, endurance and also joy and success when working with your scientific challenges in the future.

\author{
Sincerely yours \\ Hannch Hidentrose \\ Hannele Hiidenhovi \\ Doctor of Health Sciences \\ Laalahdenkatu 16 D 34 \\ 33560 Tampere \\ Finland
}


Running Head: ENDOCRINOLOGY SHARED MEDICAL APPOINTMENTS 106 
Running Head: ENDOCRINOLOGY SHARED MEDICAL APPOINTMENTS 107

\section{APPENDIX L}

\section{Staff -Oriented Quality Instrument Assigned staff number}

Please help us make your workplace a more enjoyable place to work by taking a moment to complete this survey. Your answers are important to us and will be kept confidential

Please circle the number which best describes Extremely Very

Very

How do you believe staff performed on the following 7 items

poor poor Satisfactory

Good good Excellent

(Please grade these on a scale of $1-7$, only one number per question)

1. Provided information on examination and test results

1

2

3

$\begin{array}{llll}4 & 5 & 6 & 7\end{array}$

2. Provided information on medications and their effects

1

2

3
4
5
6
7

3. Provided information on treatment options
4
5
6
7

4. Provided information on probable outcomes of illness

1

1

2

3

$\begin{array}{llll}4 & 5 & 6 & 7\end{array}$

5. Provided protection of privacy

1

7

6. Provided effective examination and medical

$\begin{array}{llll}4 & 5 & 6 & 7\end{array}$

treatment

7

7. Overall success of the visit

1

2

3

What do you like best about the appointment? 
Running Head: ENDOCRINOLOGY SHARED MEDICAL APPOINTMENTS 108

What do you like least about the appointment?

Suggestions for improvement?

Thank you for completing our Survey 


\section{Running Head: ENDOCRINOLOGY SHARED MEDICAL APPOINTMENTS}

109

\section{Appendix M}

Table 4

Pre-SMA and Post-SMA Participants Comments

\begin{tabular}{lll}
\hline Questions & Pre-SMA & \multicolumn{1}{c}{ Post-SMA } \\
\hline $\begin{array}{l}\text { What do you like } \\
\text { best about appointment? }\end{array}$ & $\begin{array}{l}\text { 1.“very good @ explaining \& } \\
\text { answering questions'. }\end{array}$ & $\begin{array}{l}\text { 1. "Get to converse w/other people- } \\
\text { where questions might not arise } \\
\text { in regular office visit. Have learned a lot! with good } \\
\text { speakers you had very helpful. Especially when my } \\
\text { insurance would not pay for wellness center education on } \\
\text { nutrition and exercise". }\end{array}$
\end{tabular}

2. “Amanda doesn't hurry me $\&$ gives me very good information. Lets me talk".

4. "seem to care"

10. "I am doing much better with my eating $\&$ exercise and controlling my sugar"

11. "Educational"
2. "Friendlieness of staff. Instructions on drugs \& causes of diseases. Learned a lot about diabetes and dangers".

3. "started on time snacks \& water was available How much I am aware of my diabetes and what I need to maintain good Readings. And improve my A1C numbers".

4. "I learned how to eat properly. O learned how to control my blood sugar and what diabetes is all about".

5. "Good review of material I already knew, but needed freshened up on. Useful information- Great reminder of things I've learned in the past".

6. "The presenters"

7. "They try to find ways help me keep med on time"

8. "Being able to ask questions"

9. "I get good information on medication \& hos to use it"

10. "The monthly meetings has helped me to regulate my sugar better. I have learned a lot about having a Diabetic problem \& how to control it. I really enjoy The program, they have and I feel Like its helping me to control my sugar".

11. "Information on diets, meds, and outcomes Friendliness of staff

Thank You!"

12. "Informentance interesting"

13. "I get to hear more about my Deise Probleme"

1. "The phone system for office is POOR. You call it rings \& then press for what you need and

\& replies office is close. \& I know you are open,
What do like least about the appointments?
"1. "Phone messages poor:

Calls cut off \& message on hold- office is closed". 


\section{Running Head: ENDOCRINOLOGY SHARED MEDICAL APPOINTMENTS}

110

4. "nothing"

7. "The staff is cheerful and. Efficient. There is very little wait time

10. "Nothing"

11. "Satisfied

4. "none"

7. "Have someone make my meals ha ha no, you all do good job".

10. "none"

11. "Ok" but I think very busy or nurse not on duty so no option but go to emergency room'.

2. "none"

3. "Class size weren't consistant. ie- one time class completely full which caused the appointment to go longer.

4. "nothing

5.“Environment. Nee more space. Cooler room

6." Having to leave presentation to be examined for blood pressure, weight, etc".

7. "Stress from other illness making it hard to keep appts"

8. "talking among some people while presentation was going on"

9. "Nothing"

10. "Nothing"

11. "Nothing"

12. "Nothing"

13. "Nothing this is a great way to learn"

1. "Either have a way can leave message \& be returned may have a problem but not emergency to go to to ER".

2 "none"

3. "Max of 8 to 10 people /class.

4. "none"

5. "None Excellent"

6 "a little less cramped room \& a separate room for exam that's a little more private"

7. "Open"

9. "Being able to read more information"

10. "none"

11. "None" 
Running Head: ENDOCRINOLOGY SHARED MEDICAL APPOINTMENTS

111

12. "Interesting"

13. "None Doing Great Job" 